SAND 81-1271

Unlimited Release

UC-11

CIRCUMFERENTIAL STRESSES AND CRACK OPENING DISPLACEMENTS AT A FRACTURED WELL BORE

W. E. Warren and P. F. Martinez

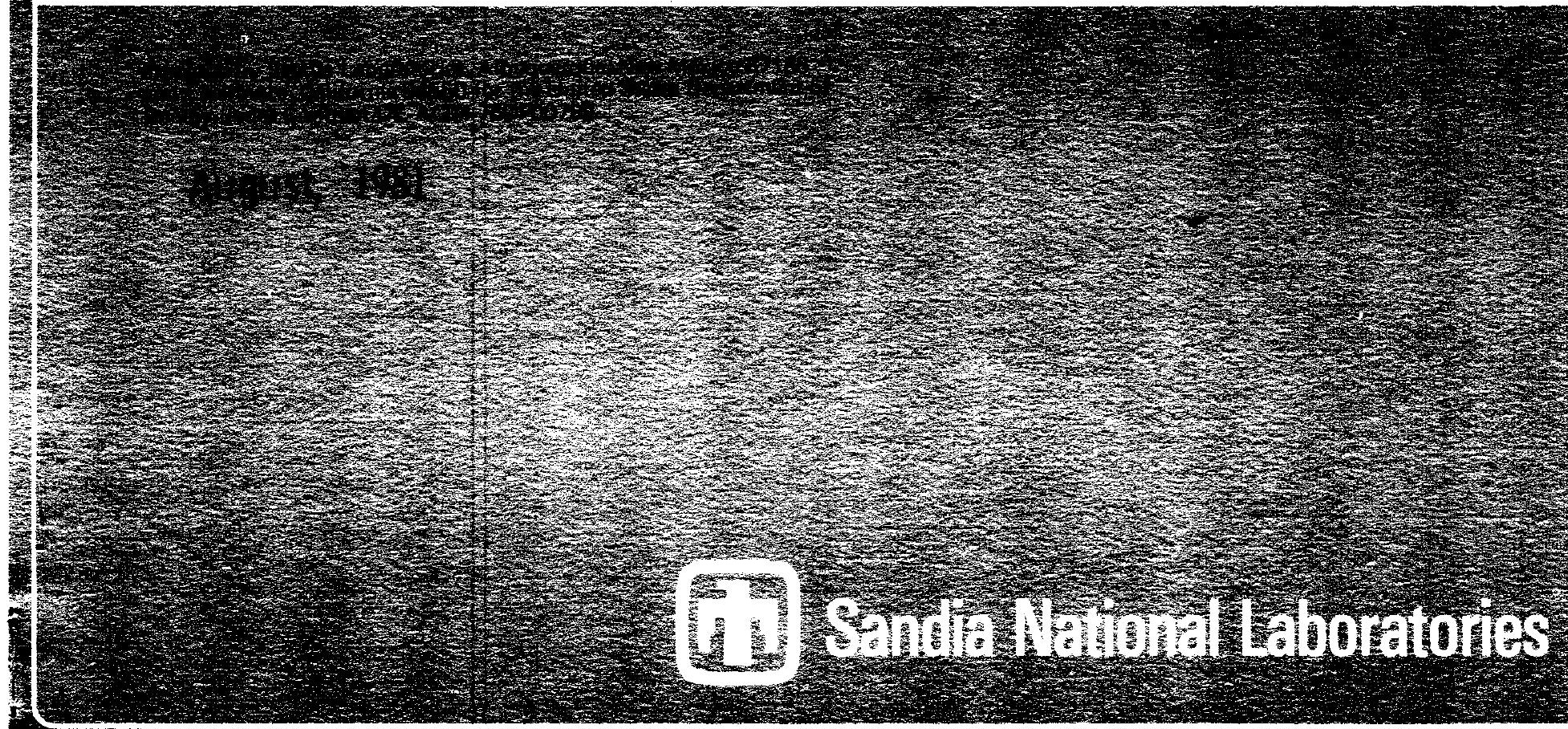


Issued by Sandia National Laboratories, operated for the United States Department of Energy by Sandia Corporation.

NOTICE: This report was prepared as an account of work sponsored by an agency of th United States Government. Neither the United States Government nor any agency thereof nor any of their employees, nor any of their contractors, subcontractors, or their employees, makes any warranty, express or implied, or assumes any legal liability or responsibility for the accuracy, completeness, or usefulress of any information, apparatus, product, or process disclosed, or represents that its uce would not infringe privately owned rights. Reference herein to any specific commexcial product, process, or service by trade name, tradera axk, manufacturer, or otherwise, does not necessarily constitute or imply its endorsement, recommendation, or favoring by the United States Government. any agency thereof or any of their contractors or subcontractors. The views and opinions expressed herein do not necessarily state ar reflect those of the United States Government, ary agency thereof or any of their contractors or subcontractors.

Printed in the United States of America

Available from

National Technical Information Service

U.S. Department of Commerce

5285 Port Royal Road

Springfield, VA 22161

Price: Printed Copy $\$ 6.00$; Microfiche $\mathrm{A} 01$ 


\title{
CIRCUMFERENTIAL STRESSES AND CRACK OPENING DISPLACEMENTS AT A
} FRACTURED WELL BORE

\author{
W. E. Warren \\ P. F. Martinez
}

Sandia National Laboratories

Albuquerque, New Mexico 87185

\begin{abstract}
Results of a plane strain analysis of the circumferential stresses around the wall of a fractured borehole and the associated crack opening displacements are presented. These borehole stresses are of considerable interest in at least two geologic applications involving the possibility of forming multiple fractures at boreholes and the measurement of in-situ stresses. For short cracks, the borehole stresses near the crack are shown to become highly compressive over a large region of the borehole. As the crack grows, the magnitude of this stress decreases but remains compressive over a larger angle around the borehole. These fracture induced stresses effectively clamp the borehole in compression and prohibit additional crack initiation and growth under quasi-static loading conditions. It is also clear that these compressive stresses and associated strains must be accounted for in any stress-relieving technique utilized for the investigation of In-situ stresses.
\end{abstract}




\section{CONTENTS}

$\underline{\text { Page }}$

Introduction ..................... 1

Analysis . . . . . . . . . . . . . . 3

Problem 1 - Pressurized Borehole with In-Situ Stresses . . 7

Problem 2 - Pressurized Borehole . . . . . . . . . . 10

Problem 3 - Borehole Jack with In-Situ Stresses . . . . 11

Results .................... 16

Problem 1 - Pressurized Borehole with In-Situ Stress . . . 16

Problem 2 - Pressurized Borehole, No In-Situ Stress . . . 20

Problem 3 - Borehole Jack with In-Situ Stresses . . . . 22

References.................. 25 


\section{Introduction}

This report presents the results of an elastic analysis of the stress and displacement fields around a fractured borehole assumed to be in plane strain. Previous investigations of this problem have been restricted to a determination of the crack tip stress intensity factor which relates directly to crack growth. Our interest here is not on crack growth but on the circumferential stresses around the wall of a fractured borehole and on the associated crack opening displacements. These borehole stresses are of considerable interest in at least two geologic applications involving the possibility of forming multiple fractures at boreholes and the measurement of in-situ stresses.

The possibility of stimulating ofl and gas production from wells by creating multiple fractures at the well bore has generated considerable interest over the last few years. Accomplishing this appears to depend upon the time frame of the loading used to fracture the borehole. High rates of loading associated with explosives often crushes the formation and the resulting plastic deformation creates an impermeable band of compressive residual stresses which effectively seals the borehole and prevents crack growth. At the other end of the rate spectrum, slow rates of loading associated with hydraulic fracturing typically create only one crack aligned normal to the maximum tensile in-situ principal stress, and the borehole stress after fracture becomes highly compressive, effectively prohibiting additional crack formation and growth. The concept of upper and lower bounds on loading rates to create multiple fractures at boreholes has been discussed by warren [1] and Schmidt et al. [2], and experimentally verified for at least one geologic formation by Warpenski 
et al [3]. Results presented here reaffirm the conclusions reached in (1) regarding the highly compressive circumferential stresses induced at the surface of the borehole by the fracture under quasi-static loading conditions.

A second problem of geologic interest is the measurement of in-situ stresses, A number of techniques, for example overcoring and hydraulic fracturing pressure records, have been used over the years to obtain estimates of these stresses. More recently, de la Cruz [4,5] has proposed a jack fracturing method to estimate these stresses. Essentially, this method combines the use of a borehole jack with a friction strain gage, and a comparison of borehole strain before loading and after fracture is then related to the borehole stresses and to the in-situ stresses. Crucial to the analysis of this data is the assumption that the borehole is relleved of circumferential stresses and strains in a neighborhood of the fracture. While the results of a finite element analysis of two symmetric cracks emanating from the borehole as presented in [4] supports this assumption, the results of this analysis for a single crack indicate the existance of highly compressive borehole stresses in a neighborhood of the fracture. These stresses remain compressive around the borehole all the way to the point of application of the jack. It Is highly unlikely that two cracks will initiate and grow simultaneously, and failure to account for these compressive strains after fracture could lead to errors in the in-situ stress estimates.

It is important to note that this analysis assumes the existence of one crack only growling out from the borehole. As shown in the Results section, this crack induces a tensile stress at the opposite side of the borehole which increases with increasing crack length and in all probability will eventually initiate a second crack at this point. The effect of this second 
crack on the borehole stresses and crack opening displacements obtained here for one crack have not been investigated but would be of interest in the geologic applications discussed above.

\section{Analysis}

We consider the plane strain linear elasticity problem of an infinite meda contain a circular cylindrical cavity of radius a as shown in Figure 1. The cavity or borehole surface is subjected to a distribution of tractions while a uniform stress state prevails at infinity. Under the action of the applied loads, a crack initiates at the cavity surface and grows out along the $x$-axis. A complete analysis of this problem is available in Reference (1] where the resulting singular integral equation is inverted utilizing the properties of Chebyshev polynomals and Gauss-Chebyshev integration [6]. We record here only the pertinent equations necessary to obtain numerical results for the specific problems considered.

Let $\mathrm{n}$ be the number of quadrature points in the Gauss-Chebyshev integration, and $N$ be an integer such that $\frac{n}{2}<N<n$ which relates to the crack length $b$ by defining

$$
\mathrm{Y}_{\mathrm{N}}=\cos \left(\frac{\pi \mathrm{N}}{\mathrm{n}}\right)<0
$$

and

$$
\frac{b}{a}=\frac{1-Y_{N}}{1+Y_{N}}>1
$$

The $(n \times n)$ system of algebraic equations 


$$
\begin{aligned}
& \sum_{k=1}^{n} \alpha_{r k} H_{k}=\tilde{\sigma}\left(y_{r}\right), r=1,2, \ldots,(n-1) . \\
& \sum_{k=1}^{n} H_{k}=0
\end{aligned}
$$

must be solved for the $\mathrm{H}_{k}$. The following definitions are used in Eqn. (3):

$$
\begin{aligned}
& \boldsymbol{\alpha}_{r k}=\frac{1}{y_{r}-t_{k}}+\ell_{r k}\left(y_{r}, t_{k}\right), x \neq N \\
& \ell_{r k}\left(y_{r}, t_{k}\right)= \begin{cases}0 & , 1<k<N, 1<r<(N-1) \\
L_{1}\left(y_{r}, t_{k}\right) & ,(N+1)<k<n, 1<r<(N-1) \\
L_{2}\left(y_{r}, t_{k}\right) & , 1<k<N,(N+1)<r<(n-1) \\
0 & ,(N+1)<k<n,(N+1)<r<(n-1)\end{cases} \\
& L_{1}\left(y_{r}, t_{k}\right)=\frac{\left(t_{k}^{2}+2 c t_{k}+1\right)}{\left(t_{k}+c\right)}\left\{\frac{1}{\left(y_{r}+c\right)^{2}}-\frac{1}{\left(t_{k}-y_{r}\right)^{2}}\right. \\
& \left.+\frac{M^{2}\left(t_{k}+c\right)\left(t_{k}^{2}+2 c t_{k}+1\right)}{\left(t_{k}-y_{r}\right)^{3}}\right\} \\
& L_{2}\left(y_{r}, t_{k}\right)=\frac{M^{2}\left(t_{k}^{2}+2 c t_{k}+1\right)}{\left(t_{k}+c\right)}\left\{1-\frac{\left(t_{k}+c\right)^{2}}{\left(t_{k}-y_{r}\right)^{2}}\right. \\
& \left.+\frac{\left(y_{r}+c\right)\left(t_{k}^{2}+2 c t_{k}+1\right)}{\left(t_{k}-y_{r}\right)^{3}}\right\} \\
& \boldsymbol{\alpha}_{\mathrm{Nk}}= \begin{cases}0 & , 1<k<\mathrm{N} \\
\frac{2 \mathrm{M}^{2}\left(\mathrm{y}_{\mathrm{N}} t_{\mathrm{k}}-1\right)}{\mathrm{Y}_{\mathrm{N}}}, & ,(\mathrm{N}+1)<\mathrm{k}<\mathrm{n}\end{cases}
\end{aligned}
$$




$$
\begin{aligned}
& t_{k}=\cos \left(\frac{\pi(2 k-1)}{2 n}\right), k=1,2, \ldots, n . \\
& y_{r}=\cos \left(\frac{\pi r}{n}\right), r=1,2, \ldots,(n-1) \\
& c=-\frac{\left(1+y_{N}^{2}\right)}{2 y_{N}} \\
& M=-\frac{2 y_{N}}{1-y_{N}^{2}}
\end{aligned}
$$

The right hand side of the system of Eqns. (3), $\widetilde{\sigma}\left(y_{r}\right)$, will be given by

$$
\tilde{\sigma}\left(y_{x}\right)=\left\{\begin{array}{l}
\sum_{2}\left(y_{r}\right), 1 \leqslant r \leqslant N \\
\sum_{1}\left(y_{r}\right),(N+1) \leqslant r \leqslant(n-1)
\end{array}\right.
$$

and represent boundary stresses on the crack surface $a<x<b$ which depend on the specific problem under investigation. Representations for $\sum_{1}\left(y_{r}\right)$ and $\sum_{2}\left(y_{Y}\right)$ of Eqn. (6) are provided under the analysis of each specific problem considered in this report.

With the $H_{k}$ evaluated, the entire stress and displacement fields in the elastic region may be obtained through Gauss-Chebyshev integration [1]. Of interest here is the circumferential or hoop stress $\sigma_{\theta \theta}(\theta)$ at the cavity surface and the crack opening displacement $w(x)$ along the crack surface. We write the circumferential stress $\sigma_{\theta \theta}(\theta)$ in the form

$$
\sigma_{\theta \theta}(\theta)=\stackrel{\circ}{\circ} \sigma_{\theta \theta}^{*}(\theta)+\sigma_{\theta \theta}(\theta),
$$

where $\stackrel{\circ}{\sigma \theta}_{\theta}(\theta)$ is the stress due to the applied tractions just prior to fracture initiation, and $\sigma_{\theta \theta}^{*}(\theta)$ arises from the presence of the crack. While both of 
these contributions depend upon the specific problem being considered, we represent $\sigma_{\theta \theta}^{*}(\theta)$ in the form

$$
\sigma_{\theta \theta}^{*}(\theta)=s_{1}(\theta)+s_{2}(\theta)+\sum_{2}\left(y_{N}\right)
$$

where

$$
\begin{aligned}
& s_{1}(\theta)=8 M^{2}\left(1-\cos ^{2} \theta\right) \sum_{k=1}^{N} H_{k} \frac{\left(t_{k}+c\right)\left[1-M\left(t_{k}+c\right) \cos \theta\right]}{\left[1+M^{2}\left(t_{k}+c\right)^{2}-2 M\left(t_{k}+c\right) \cos \theta\right]^{2}} \\
& s_{2}(\theta)=2 M(1-\cos \theta) \sum_{k=1}^{N} H_{k}
\end{aligned}
$$

Combining Eqns. (7) and (8), the circumferential stress becomes

$$
\sigma_{\theta \theta}(\theta)=s_{1}(\theta)+s_{2}(\theta)+\hat{\sigma}_{\theta \theta}(\theta)
$$

where $\hat{\sigma}_{\theta \theta}(\theta)$ includes $\sigma_{\theta \theta}^{\circ}(\theta)$ and depends on the spectfic problem and is provided under the analysis of each problem considered in this report. The crack opening displacement is available only at the discrete points $x_{r}$ given by

$$
x_{r / a}=M\left(y_{r}+c\right), 1<r<N
$$

and these points, the normalized displacement is

$$
\frac{G W\left(x_{r}\right)}{2 \pi a(1-v)}=M \sum_{k=1}^{r} H_{k}
$$

where $G$ is the material shear modulus and $\nu$ is the material poisson's ratio. since $x_{N}=a$, the crack opening displacement at the borehole is 


$$
\frac{G W(a)}{2 \pi a(1-v)}=M \sum_{k=1}^{N} H_{k}
$$

which also relates directly to $s_{2}(\theta)$. Of possible interest is the circumferential stress at $\theta=180^{\circ}$ since another crack could initiate at this point. This stress is readily obtalned from Eqns. (9) and (12) as

$$
\sigma_{\theta \theta}\left(180^{\circ}\right)=4\left[\frac{G W(a)}{2 \pi a(1-v)}\right]+\hat{\sigma}_{\theta \theta}\left(180^{\circ}\right)
$$

We now consider specific problems.

Problem 1 - Pressurized Borehole with In-Situ Stresses

In this problem, we consider a uniform stress system $\sigma_{x}<\sigma_{y}$ in the far field while the borehole surface is subjected to a uniform pressure $p_{0}$. This problem relates to the formation of multiple fractures at the borehole under quasi-static loading conditions and is discussed extensively in Ref. [1]. Prior to fracture, the circumferential stress at the borehole is

$$
\stackrel{\circ}{\sigma_{\theta \theta}(\theta)}=\left(p_{0}+\sigma_{x}+\sigma_{y}\right)+2\left(\sigma_{y}-\sigma_{x}\right) \cos 2 \theta
$$

which is a maximum at $\theta=0$. After fracture initiates at this point and proceeds out along the x-axis, fluid from the borehole will flow out into the crack and pressurize the crack surface. While the actual pressure distribution on the crack surface is quite complex $[7,8,9]$, we consider here four simplified cases which are representative of the actual system under certain conditions. Denoting this pressure distribution as $p^{*}(x)$, the boundary stress $\sigma_{y y}(x)$ on the crack surface $a<x<b$ is given by [1]

$$
\sigma_{y y}(x)=\frac{-1}{2}\left(2 p_{0}+\sigma_{x}+\sigma_{y}\right)(a / x)^{2}+\frac{3}{2}\left(\sigma_{x}-\sigma_{y}\right)(a / x)^{4}-\sigma_{y}-p^{*}(x) .
$$




\section{(1) Cage 1: $p *(x)=0$}

This case provides no pressure on the crack face and is representative of relatively short fractures and short times during which sufficient fluid has not entered the crack to induce pressures. This case is considered in [1], and the relevant terms of Eqns. (6) and (9) become

$$
\begin{aligned}
& \sum_{1}\left(y_{x}\right)=-\frac{1}{2}\left(2 p_{0}+\sigma_{x}+\sigma_{y}\right)+\frac{3}{2}\left(\sigma_{x}-\sigma_{y}\right) \frac{1}{g_{x}}-\sigma_{y} g_{r}, \\
& \sum_{2}\left(y_{x}\right)=-\frac{1}{2}\left(2 p_{0}+\sigma_{x}+\sigma_{y}\right) g_{r}+\frac{3}{2}\left(\sigma_{x}-\sigma_{y}\right) g_{x}^{2}-\sigma_{y}, \\
& \hat{\sigma}_{\theta \theta}(\theta)=4\left(\sigma_{x}-\sigma_{y}\right)\left(1-\cos ^{2} \theta\right),
\end{aligned}
$$

where

$$
g_{r}=\frac{1}{M^{2}\left(y_{r}+c\right)^{2}}
$$

(ii) Case 2: $\mathrm{p}^{*}(\mathrm{x})=\mathrm{p}_{\mathrm{O}}$

This case provides a uniform pressure equal to the borehole pressure along the entire crack face and is representative of a stationary crack for long times where the pressure of the fluid in the crack has stabilized. This case is also considered in [1], and the relevant terms of Eqns. (6) and (9) become

$$
\begin{aligned}
& \sum_{1}\left(y_{r}\right)=-\frac{1}{2}\left(2 p_{0}+\sigma_{x}+\sigma_{y}\right)+\frac{3}{2}\left(\sigma_{x}-\sigma_{y}\right) \frac{1}{g_{r}}-\left(\sigma_{y}+p_{o}\right) g_{r}, \\
& \sum_{2}\left(y_{r}\right)=-\frac{1}{2}\left(2 p_{0}+\sigma_{x}+\sigma_{y}\right) g_{x}+\frac{3}{2}\left(\sigma_{x}-\sigma_{y}\right) g_{r}^{2}-\left(\sigma_{y}+p_{o}\right), \\
& \hat{\sigma}_{\theta \theta}(\theta)=4\left(\sigma_{x}-\sigma_{y}\right)\left(1-\cos ^{2} \theta\right)-p_{0} .
\end{aligned}
$$


(iii) Case 3: $p^{*}(x)=p_{0} \frac{(b-x)}{(b-a)}$

This case provides a linearly varying pressure on the crack face which is equal to the borehole pressure at the borehole $x=a$, and goes to zero at the crack tip, $x=b$. This distribution may be representative under certain conditions of uniform crack growth. The terms in Eqns. (6) and (9) for this pressure become

$$
\begin{aligned}
\Sigma_{1}\left(y_{r}\right)= & -\frac{1}{2}\left(2 p_{0}+\sigma_{x}+\sigma_{y}\right)+\frac{3}{2}\left(\sigma_{x}-\sigma_{y}\right) \frac{1}{g_{r}} \\
& -\sigma_{y} g_{x}-p_{o} g_{r}^{3 / 2} \frac{\left(1+y_{r}\right)}{\left(1+y_{N}\right)}, \\
\sum_{2}\left(y_{r}\right)= & -\frac{1}{2}\left(2 p_{0}+\sigma_{x}+\sigma_{y}\right) g_{r}+\frac{3}{2}\left(\sigma_{x}-\sigma_{y}\right) g_{r}^{2}-\sigma_{y} \\
& -p_{0} \frac{\left(1-y_{Y}\right)}{\left(1-y_{N}\right)}, \\
\hat{\sigma}_{\theta \theta}(\theta)= & 4\left(\sigma_{x}-\sigma_{y}\right)\left(1-\cos ^{2} \theta\right)-p_{0} .
\end{aligned}
$$

(iv) Case 4: $p^{*}(x)=p_{0} \frac{\sqrt{b-x}}{(b-a)} \sqrt{b+x-2 a}$

This case provides a parabolic pressure variation on the crack face which is equal to the borehole pressure at $x=a$ and vanishes at the crack tip, $x=b$. Like Case 3, this distribution may be representative of the fluid pressure in the crack under dynamic conditions of crack growth. The terms in Eqns. (6) and (9) for this case become

$$
\begin{aligned}
L_{I}\left(y_{r}\right)= & -\frac{1}{2}\left(2 p_{O}+\sigma_{x}+\sigma_{y}\right)+\frac{3}{2}\left(\sigma_{x}-\sigma_{y}\right) \frac{1}{g_{r}}-\sigma_{y} g_{r} \\
& -p_{O} g_{r}^{3 / 2} \frac{\sqrt{1+y_{r}}}{\left(1+y_{N}\right)}\left[\frac{\left(1+y_{N}+2 y_{N}^{2}\right)}{\left(1-y_{N}\right)}-\frac{\left(1+3 y_{N}\right)}{\left(1-y_{N}\right)} y_{r}\right]^{1 / 2}
\end{aligned}
$$




$$
\begin{aligned}
l_{2}\left(y_{r}\right)= & -\frac{1}{2}\left(2 p_{0}+\sigma_{x}+\sigma_{y}\right) g_{r}+\frac{3}{2}\left(\sigma_{x}-\sigma_{y}\right) g_{r}^{2}-\sigma_{y} \\
& -p_{O} \frac{\sqrt{1-y_{r}}}{\left(1-y_{N}\right)}\left[1-2 y_{N}+y_{Y}\right]^{1 / 2}, \\
\sigma_{\theta \theta}(\theta)= & 4\left(\sigma_{x}-\sigma_{y}\right)\left(1-\cos ^{2} \theta\right)-p_{O} .
\end{aligned}
$$

Problem 2 - Pressurized Borehole

To assess the effect of the uniform in-situ stresses on the borehole stresses and crack opening displacements of Prob. 1, this problem considers the effect of the borehole pressure only. Prior to fracture, the circumferential stress on the borehole is $\stackrel{\circ}{\theta \theta}^{\circ}=p_{0}$ and we assume fracture initiates at $\theta=0$. All the relevant terms of Eqns. (6) and (9) may be obtained from the previous analysis of Prob. 1 by taking $\sigma_{x}=\sigma_{y}=0$, but we reproduce them here as separate cases since the results for this problem are discussed separately. We consider only the two limiting crack surface pressure distributions, $p^{*}(x)=0$ and $p^{*}(x)=p_{O}$, since these are sufficient to provide a comparison of the effects of the in-situ uniform stresses. Accordingly, we now record the information for cases 5 and 6 .

(v) Case 5: $\mathrm{p}^{\star}(\mathrm{x})=0$

Taking $\sigma_{x}=\sigma_{y}=0$ in Case 1, Eqn. (16) gives

$$
\begin{aligned}
& \sum_{1}\left(y_{r}\right)=-p_{0}, \\
& \sum_{2}\left(y_{r}\right)=-p_{0} g_{r}, \\
& \sigma_{\theta \theta}(\theta)=0
\end{aligned}
$$


(vi) Case 6: $p^{\star}(x)=p_{0}$

Taking $\sigma_{x}=\sigma_{y}=0$ in Case 2, Eqn. (18) gives

$$
\begin{aligned}
& \sum_{1}\left(y_{r}\right)=\sum_{2}\left(y_{r}\right)=-p_{0}\left(1+g_{r}\right), \\
& \hat{\sigma}_{\theta \theta}(\theta)=-p_{0} .
\end{aligned}
$$

\section{Problem 3 - Borehole Jack With In-Situ Stresses}

A recently developed technique for estimating in-situ stresses by measuring the change in borehole strain near a fracture induced by a borehole jack $[4,5]$ has promoted an interest in the nature of the circumferential stresses near such a fractured borehole. In application, the borehole jack provides equal compressive tractions on opposite sides of the borehole causing a fracture to initiate on a plane perpendicular to these applied 1oads. In the device developed by de la cruz [4], these tractions are applied over the surface of the borehole approximately defined by $\pi / 4<$ $\theta<\frac{3 \pi}{4}$ and $\frac{5 \pi}{4}<\theta<\frac{7 \pi}{4}$, where $\theta$ is measured as in Fig. 1 . While a detailed analysis of the contact stresses at the borehole surface is provided In Ref. [5], we will here consider two idealized cases which provide equal and opposite resultant forces on the upper and lower portions of the borehole and which have the advantage of relatively simple closed form elasticity solutions. The main purpose of this analysis is to demonstrate that the circumferential stresses at the borehole do not go to zero near the fracture but become highly compressive, and that self-equilibrated variations in the contact stress under the jack will have only a slight effect on these circumferential stress results. To obtain the stress and displacement fields around the unfractured borehole which arise from the effects of the jack only, we make use of the complex potentlals $\Phi(z)$ and $\Psi(z)$ of Muskhelishvili [10] which give the stress field in the form 


$$
\begin{aligned}
\sigma_{x x}+\sigma_{Y y}=\sigma_{Y x}+\sigma_{\theta \theta} & =2[\Phi(z)+\overline{\Phi(z)}] \\
\sigma_{Y Y}-\sigma_{X x}+2 i \sigma_{x y} & =2\left[\bar{z} \Phi^{-}(z)+\Psi(z)\right], \\
\sigma_{\theta \theta}-\sigma_{r Y}+2 i \sigma_{r \theta} & =2 e^{i 2 \theta}\left[\bar{z} \Phi^{\prime}(z)+\Psi(z)\right],
\end{aligned}
$$

where $\sigma_{x x}, \sigma_{y y}, \sigma_{x y}$ are the Cartesian components of the two-dimensional

stress tensor, and $\sigma_{r r}, \sigma_{\theta \theta}, \sigma_{r \theta}$ are polar components of this tensor. We now consider the potentials $\Phi(z)$ and $\Psi(z)$ and develop the necessary stress relations for the two idealized problems as Cases 7 and 8 below.

\section{(vii) Case 7: Cosine Contact Traction}

For this case we assume that the contact effect of the jack provides boundary stresses on the borehole given by

$$
\begin{aligned}
& \sigma_{r r}(\theta)= \begin{cases}0 \quad,-\pi / 4<\theta<\pi / 4, \frac{3 \pi}{4}<\theta<\frac{5 \pi}{4} \\
\sigma_{0} \cos 2 \theta \quad, \pi / 4<\theta<\frac{3 \pi}{4}, \frac{5 \pi}{4}<\theta<\frac{7 \pi}{4}\end{cases} \\
& \sigma_{r \theta}(\theta)=0 \quad, 0 \leqslant \theta \leqslant 2 \pi
\end{aligned}
$$

where $\sigma_{0}$ is a constant related to the force $F_{Y}$ applied per unit length along the borehole by the upper or lower portions of the jack such that

$$
F_{y}=\frac{2}{3} \sqrt{2} \text { a } \sigma_{0}
$$

The appropriate complex potential functions which satisfy (24) and the condition that the stress field vanish at infinity are 


$$
\begin{aligned}
& \Phi(z)=\sigma_{\circ}\left\{\frac{1}{2 \pi}+\frac{1}{4}\left(\frac{a}{z}\right)^{2}-\frac{1}{2 \pi}\left[1+\left(\frac{a}{z}\right)^{4}\right]\left(\frac{z}{a}\right)^{2} \tan ^{-1}\left(\frac{a}{z}\right)^{2}\right\} \\
& \Psi(z)=\sigma_{\circ}\left\{\frac{1}{2}\left(\frac{a}{z}\right)^{4}+\frac{1}{\pi}\left[1-\left(\frac{a}{z}\right)^{4}\right] \tan ^{-1}\left(\frac{a}{z}\right)^{2}\right\} .
\end{aligned}
$$

On the cavity surface $z=a e^{i \theta}$, the circumferential stress from this solution becomes

$$
\sigma_{\theta \theta}(\theta)=\left\{\begin{array}{l}
\frac{2 \sigma_{0}}{\pi},-\frac{\pi}{4}<\theta<\frac{\pi}{4}, \frac{3 \pi}{4}<\theta<\frac{5 \pi}{4} \\
\frac{2 \sigma_{0}}{\pi}+\sigma_{0} \cos 2 \theta, \frac{\pi}{4}<\theta<\frac{3 \pi}{4}, \frac{5 \pi}{4}<\theta<\frac{7 \pi}{4},
\end{array}\right.
$$

and the stress along the $x$-axis, $x>a$, is given by

$$
\sigma_{Y Y}(x)=\sigma_{\circ}\left\{\frac{2}{\pi}+\frac{1}{2}\left(\frac{a}{x}\right)^{4}+\frac{1}{\pi}\left[1-\left(\frac{a}{x}\right)^{4}-2\left(\frac{x}{a}\right)^{2}\right] \tan ^{-1}\left(\frac{a}{x}\right)^{2}\right\}
$$

Superimposing these results with the solution for a uniform in-situ stress state provides the terms for Eqns. (6) and (9) in the form

$$
\begin{aligned}
\sum_{1}\left(y_{x}\right)= & -\frac{1}{2}\left(\sigma_{x}+\sigma_{y}\right)+\frac{3}{2}\left(\sigma_{x}-\sigma_{y}\right) \frac{1}{g_{r}}-\sigma_{y} g_{r} \\
& -\sigma_{0}\left[\frac{2}{\pi} g_{r}+\frac{1}{2 g_{r}}+\frac{1}{\pi} g_{r}\left(1-\frac{1}{g_{r}^{2}}-2 g_{r}\right) \tan ^{-1}\left(\frac{1}{g_{r}}\right)\right] \\
\sum_{2}\left(y_{r}\right)= & -\frac{1}{2}\left(\sigma_{x}+\sigma_{y}\right) g_{r}+\frac{3}{2}\left(\sigma_{x}-\sigma_{y}\right) g_{r}^{2}-\sigma_{y} \\
& -\sigma_{0}\left[\frac{2}{\pi}+\frac{1}{2} g_{x}^{2}+\frac{1}{\pi}\left(1-g_{r}^{2}-\frac{2}{g_{r}}\right) \tan ^{-1}\left(g_{Y}\right)\right] \\
\hat{\sigma}_{\theta \theta}(\theta)= & 4\left(\sigma_{x}-\sigma_{y}\right)\left(1-\cos ^{2} \theta\right)
\end{aligned}
$$

where $g_{r}$ is given by Eqn. (17). . 
(viii) Case 8: Uniform Contact Traction.

For this case the contact effect of the jack is assumed to provide a uniform radial stress over the contact area providing boundary stresses on the borehole given by

$$
\begin{aligned}
& \sigma_{r r}(\theta)=\left\{\begin{array}{c}
0,-\pi / 4<\theta<\pi / 4, \frac{3 \pi}{4}<\theta \frac{5 \pi}{4} \\
-\sigma_{1}, \frac{\pi}{4}<\theta<\frac{3 \pi}{4}, \frac{5 \pi}{4}<\theta<\frac{7 \pi}{4} \\
\sigma_{r \theta}(\theta)=0 \quad, 0<\theta<2 \pi
\end{array}\right.
\end{aligned}
$$

In terms of $\sigma_{1}$, the force $F_{y}$ applied by the upper or lower portions of the jack is

$$
F_{Y}=\sqrt{2} a \sigma_{I}
$$

and we note from Eqn. (25) that if we take $\sigma_{1}=\frac{2}{3} \sigma_{0}$, the force applied by the jack is identical for both case 7 and case 8. The complex potential functlons which satisfy $(28)$ and provide a stress field vanishing at infinity are

$$
\begin{aligned}
& \Phi(z)=\frac{\sigma_{1}}{\pi} \tan ^{-1}(a / z)^{2} \\
& \Psi(z)=\sigma_{1}\left(\frac{a}{z}\right)^{2}\left\{\frac{1}{2}+\frac{2}{\pi} \frac{(a / z)^{2}}{\left[1+(a / z)^{4}\right]}\right\}
\end{aligned}
$$

and on the cavity surface $z=a e^{i \theta}$, the circumferential stress is

$$
\sigma_{\theta \theta}(\theta)= \begin{cases}\sigma_{1}, & -\pi / 4<\theta<\pi / 4, \frac{3 \pi}{4}<\theta<\frac{5 \pi}{4} \\ 0 \quad, \pi / 4<\theta<\frac{3 \pi}{4}, \frac{5 \pi}{4}<\theta<\frac{7 \pi}{4}\end{cases}
$$


The stress along the $x$-axis, $x>a$, is

$$
\sigma_{Y Y}(x)=\sigma_{1}\left\{\frac{1}{2}\left(\frac{a}{x}\right)^{2}-\frac{2}{\pi}\left(\frac{a}{x}\right)^{2} \frac{\left[1-(a / x)^{2}\right]}{\left[1+(a / x)^{4}\right]}+\frac{2}{\pi} \tan ^{-1}\left(\frac{a}{x}\right)^{2}\right\} .
$$

Superimposing these results with the solution for a uniform in-situ stress state provides the terms for Eqns. (6) and (9) as

$$
\begin{aligned}
\sum_{1}\left(y_{r}\right)= & -\frac{1}{2}\left(\sigma_{x}+\sigma_{y}\right)+\frac{3}{2}\left(\sigma_{x}-\sigma_{y}\right) \frac{1}{g_{r}}-\sigma_{y} g_{r} \\
& -\sigma_{1}\left[\frac{1}{2}-\frac{2}{\pi} g_{r} \frac{\left(g_{r}-1\right)}{\left(1+g_{r}^{2}\right)}+\frac{2}{\pi} g_{r} \tan ^{-1}\left(1 / g_{r}\right)\right] \\
\sum_{2}\left(y_{r}\right)= & -\frac{1}{2}\left(\sigma_{x}+\sigma_{y}\right) g_{r}+\frac{3}{2}\left(\sigma_{x}-\sigma_{y}\right) g_{r}^{2}-\sigma_{y} \\
& -\sigma_{1}\left[\frac{1}{2} g_{r}-\frac{2}{\pi} g_{r} \frac{\left(1-g_{r}\right)}{\left(1+g_{r}^{2}\right)}+\frac{2}{\pi} \tan ^{-1}\left(g_{r}\right)\right] \\
\hat{\sigma}_{\theta \theta}(\theta)= & 4\left(\sigma_{x}-\sigma_{y}\right)\left(1-\cos ^{2} \theta\right),
\end{aligned}
$$

with $g_{x}$ given by Eqn. (17).

(ix) Case 9: Uniform Contact Traction, Zero In-Situ Stress.

This case is the same as case 8 with $\sigma_{x}=\sigma_{y}=0$ and we consider this case as a means of evaluating the relative contribution of the borehole jack induced stresses and the in-situ stresses on the stresses at the borehole. Thus setting $\sigma_{x}=\sigma_{y}=0$ in Eqns. (31), the terms for Eqns. (6) and (9) become 


$$
\begin{aligned}
& \sum_{l}\left(y_{r}\right)=-\sigma_{1}\left[\frac{1}{2}-\frac{2}{\pi} g_{r} \frac{\left(g_{r}-1\right)}{\left(l+g_{r}^{2}\right)}+\frac{2}{\pi} g_{r} \tan ^{-1}\left(l / g_{r}\right)\right], \\
& L_{2}\left(y_{r}\right)=-\sigma_{1}\left[\frac{1}{2} g_{r}-\frac{2}{\pi} g_{r} \frac{\left(1-g_{r}\right)}{\left(1+g_{r}^{2}\right)}+\frac{2}{\pi} \tan ^{-1}\left(g_{r}\right)\right], \\
& \hat{\sigma}_{\theta \theta}(\theta)=0 .
\end{aligned}
$$

\section{Results}

We present here the numerical results obtained in the solution of each of the problems defined in the Analysis section. For problems 1 and 3 the non-zero in-situ stress field is taken as $\sigma_{X}=-1500$ psi and $\sigma_{Y}=-500$ psi which are the same values considered in Ref. [1]. All results were obtained using $n=200$ which provides 200 quadrature points in the Gauss-Chebyshev Integration and appears to be adequate. Trial calculations were carried out for the problems of Case 1 with $n=100,125,150,175$ and 190 with convergence toward the results for $\mathrm{n}=200$ noted. The difference between results for $\mathrm{n}=$ 190 and 200 is less than 0.108 for the stress and less than 0.038 for crack opening.

\section{Problem 1 - Pressurized Borehole With In-Situ Stress}

For this problem we take $p_{0}=5000$ psi which is representative of a cavity loaded by a relatively slowly burning propellant as used in recent multiple fracture experiments [3] and is also the pressure level considered in Ref. [1]. With $\sigma_{x}=-1500 \mathrm{psi}$ and $\sigma_{y}=-500 \mathrm{psi}$, the circumferential borehole stress before fracture for Cases 1 to 4 as given by Eqn. (14) becomes

$$
\stackrel{\circ}{\sigma_{\theta \theta}(\theta)}=\left(1+4 \cos ^{2} \theta\right) \times 10^{3} \mathrm{psi}
$$


which is maximum at $\theta=0^{\circ}$ and well above the tensile strength of most geologic formations. Following crack initiation and growth, the pressurized fluid in the borehole will flow into the crack and pressurize the crack surface with a pressure $p^{\star}(x), a<x<b$. The four cases considered in this problem represent four different possible pressure distributions as follows:

\section{(1) Case 1: $\mathrm{p}^{*}(\mathrm{x})=0$.}

This distribution is valid for short cracks and for small times after crack initiation where fluid flow into the crack is not sufficient to induce a pressure. Crack growth for this distribution is limited. The clamping effect of the in-gitu stresses induces a negative stress intensity factor at the crack tip which is superimposed with the positive stress intensity factor arising from the pressurized borehole. For short cracks, the net stress intensity factor is positive, decreasing with increasing crack length and eventually going to zero, terminating crack growth. For this problem, the limiting crack length is $(b / a) \sim 7.0$. For most materials, crack growth terminates when the crack tip stress intensity factor becomes less than some positive critical value and the actual limiting crack length will be less than that assumed here.

(11) Case 2: $p^{*}(x)=p_{0}$.

This distribution provides a uniform pressure on the crack face and is valld for any length static crack after sufficient time has elapsed for the pressure in the borehole and crack to equalize. For this distribution there is no limiting crack length.

(iii) Case 3: $p^{*}(x)=p_{0}(b-x) /(b-a)$.

This linear distribution represents a possible pressure on the faces of a growing crack and is equal to the borehole pressure at the borehole while 
going to zero at the crack tip. There is no limiting crack length for this pressure distribution.

(iv) Case 4: $p^{*}(x)=p_{0} \frac{\sqrt{b-x}}{(b-a)} \sqrt{b+x-2 a}$.

This parabolic distribution, like Case 3, represents a possible pressure during crack growth. There is also no limiting crack length for this pressure distribution.

Tables 1, 2, and 3 show the circumferential stress $\sigma_{\theta \theta}(\theta)$ around the borehole for these four cases for three different crack lengths. For the shortest crack, $b / a=1.89$ of Table 1 , all four cases behave essentially the same, exhibiting a very highly conpressive stress region near the crack, remalning compressive for a considerable distance around the borehole, eventually becoming tensile at some point less than $90^{\circ}$ from the crack. For $p^{\star}(x)=0$ of Case 1 , the stress becomes tensile at about $35^{\circ}$, while for all the non-zero $p^{*}(x)$ the stress remains compressive through $80^{\circ}$. The clamping effect of this highly compressive stress on the suppression of multiple fractures at a borehole has been discussed in Ref. [1].

Results presented in Table 2 for a longer crack, $b / a=3.85$ are quite similar to the results for the shorter crack. The peak compressive stresses are considerably reduced but the stresses remain compressive over a larger region of the borehole. Again, for $p^{*}=0$ of Case 1 , the stress becomes tensile at about $50^{\circ}$, while the other three cases remain compressive up to $90^{\circ}$. While increased crack length reduces peak compressive stresses, the region of compressive stress around the borehole is increased.

Table 3 shows how the circumferential stress distribution is changed for a long crack, $b / a=9.47$. This is beyond the crack length limit of case $l$ as discussed, and for the three cases of pressurized cracks we observe quite 
similar behavior. The stress becomes tensile very close to the crack, exhibiting a tensile stress peak rather than compressive as in the case of the shorter cracks, becoming compressive again between 4 and $10^{\circ}$ from the crack. The stresses then remain compressive up to $90^{\circ}$.

The crack opening displacements for these three crack lengths are shown in Figs. 2, 3, and 4. We note the vertical slope of the displacement curves at the crack tip indicative of the square root stress singularity at this point. Of particular interest is the large negative slope of the crack opening curves at the borehole $x / a=1$ for the short cracks of Figs, 2 and 3 . This sharp change indicates rather severe deformation of an element of material at the intersection of the crack with the borehole. A possible interpretation of this deformation is shown in Fig. 5 where the square element $A B C D$ at the borehole prior to fracture fans out into the element $A^{\prime} B^{\prime} C^{\prime} D^{\prime}$ after fracture. This severe fanning deformation can be interpreted as inducing a highly localized and severe bending action to this element of material which gives rise to the highly compressive circumferential stresses in a neighborhood of $A^{\prime}$ as evidenced by the stresses of Tables 1 and 2 .

The crack opening displacements for long cracks shown in Fig. 4 demonstrate a similar effect but in the opposite direction. Here the crack surface has a positive slope at the borehole rather than negative and the corner element shown in Fig. 5 will tend to be collapsed down. This induces relatively large localized tensile stresses at the borehole as shown in Table 3.

It is important to note that all these results are for a single crack inftiating at $\theta=0$ and growing out along the positive real axis. The borehole stress at this point at the time of crack initiation is $\sigma_{\theta \theta}^{0}(0)=5 \times 10^{3}$ psi. Tables 1, 2, and 3 show the stress at the opposite side of the borehole, $\theta=180^{\circ}$, to be greater than this stress and to become even greater with increasing crack 
length. It is thus quite probable that a second crack will initiate opposite the first, and the effect of th1s second crack on the stresses due to the first. as well as the shape of the crack opening displacement could be significant. This effect would undoubtedly be more pronounced for large crack lengths. The analysis of two cracks has not been carried out but should be of interest in the investigation of creating multiple fractures at boreholes.

\section{Problem 2 - Pressurized Borehole, No In-Situ Stress.}

This problem assesses the effect of the uniform in-situ stresses on the borehole stresses and crack opening displacements of Prob. 1 . We take $p_{0}=$ $5000 \mathrm{ps} 1$ and the circumferential stress on the borehole prior to fracture is

$$
\stackrel{0}{\sigma_{\theta \theta}}(\theta)=p_{0}=5 \times 10^{3} \mathrm{psi}
$$

and we again assume that fracture initiates at $\theta=0$. Following crack growth, we assume that the pressurized fluid in the borehole flows into the crack and pressurizes the crack surfaces with a pressure $p^{*}(x)$. For this problem we conslder only two cases which are analogous to Cases 1 and 2 of Problem 1.

\section{(v) Case 5: $p^{*}(x)=0$.}

This distribution is the same as Case 1 and valid under the same conditions. Unlike Case 1, however, in the absence of in-situ stresses there is no limit to crack growth since the crack tip stress intensity factor is always positive. For real materials where crack growth will not occur for stress intensity factors less than some critical value, crack growth will be limited but we do not consider that situation here.

(vi) Case 6: $\mathrm{p}^{*}(\mathrm{x})=\mathrm{p}_{\mathrm{O}}$.

This distribution is the same as Case 2 and valid under the same conditions. There is no limit to crack growth. 
Table 4 shows the circumferential stress $\sigma_{\theta \theta}(\theta)$ around the borehole for these two cases and for the three crack lengths presented for Prob. 1 . For short cracks, $b / a=1.89$, the stress distribution for Prob. 1 and Prob. 2 are quite similar. The in-situ conpressive stresses tend to increase the peak circumferential compressive stresses and to increase the angle around the borehole at which this stress becomes tensile.

For the intermediate length cracks, $b / a=3.85$, Case 1 and 5 for $p^{\star}(x)=0$ are quite similar, the compressive circumferential stresses of Case 1 again being greater than Case 5 and the angle at which this stress becomes positive being larger for Case 1. Cases 2 and 6 for this crack length exhibit somewhat different behavior indicating the effect of in-situ stresses. The circumferential stresses for all six cases for this crack length are shown, for comparison, in Fig. 6 .

Results for the long cracks, $b / a=9.47$, show similar behavior for Cases 2 and 6 for $p^{*}(x)=p_{0}$, the in-situ compressive stresses of case 2 reducing the peak tensile stresses at the borehole. This long crack length is greater than the limiting crack length for Case 1, but Case 5 for this crack length continues to exhibit the same general behavior as for the shorter cracks, remaining compressive for a considerable distance around the borehole.

The crack opening displacements for Cases 5 and 6 of Prob. 2 are shown in Figs. 2, 3, and 4 for comparison with Prob. 1. The clamping effect of the in-situ compressive stresses is clearly evident. While the crack opening displacements are larger for Prob. 2, the crack openings at the borehole are quite close indicating that the crack opening displacement at the borehole is not highly dependent on the magnitudes of the in-situ stresses. We note again the relation between the slope of the crack opening displacement at the borehole and the large compressive or tensile stresses near the crack corner as 
discussed under Prob. 1. Also, the large tenslle stresses on the borehole at $\theta=180^{\circ}$ may induce a second fracture at this point and alter these stress and displacement distributions.

\section{Problem 3 - Borehole Jack With In-Situ Stresses.}

For this problem, opposite sides of the borehole are loaded with a jack which induces stresses around the borehole as discussed under cases 7 and 8 in the Analysis section. With $\sigma_{x}=-1500$ psi and $\sigma_{y}=-500$ psi, the circumferential borehole stress before fracture for case 7 becomes

$$
\sigma_{\theta \theta}^{\circ}(\theta)=-4\left(1-\cos ^{2} \theta\right) \times 10^{3} \mathrm{ps} 1+\frac{2}{\pi} \sigma_{0},-\frac{\pi}{4}<\theta<\frac{\pi}{4} \text {, }
$$

and the fack loading $F_{y}$ of Eqn. (25) must be sufficient so that $\frac{2}{\pi} \sigma_{0}$ is greater than the material tensile strength. For the numerical work we take $\sigma_{0}=1000 \mathrm{psi}$ to $5000 \mathrm{psi}$ in increments of $1000 \mathrm{psi}$ in the Eqns. (27) for Case 7. For this loading condition there is no pressurized fluid in the borehole which can flow into and pressurize the crack and so the crack surface for this problem remains stress free. The clamping effect of the compressive in-situ stresses produces a negative stress intensity factor at the crack tip which eventually annihilates the positive stress intensity factor produced by the borehole jack loading and effectively provides a limit to crack growth under these loading conditions. Results of the numerical analysis give the values for this limiting crack length, and the crack opening displacements at the limiting crack length for each of the five jack loadings is shown in Fig. 7. At this limiting crack length, the stress intensity factor is zero resulting in a cusp closing of the crack tip as shown. Actual crack growth in a given material will not reach this limiting value since crack growth will terminate when the stress intensity factor becomes less than the value of the 
critical stress intensity factor for the material. We aqain note the very large negative crack opening gradient at the borehole $(x / a)=1$ shown in Fig. 7 which is assoclated with the large compressive stresses as discussed for Prob. 1. These circumferential stresses are shown in Fig. 8 for the limiting crack length associated with each jack load. These stresses exhibit a highly localized compressive peak very close to the crack at $\theta=0$ and remain compressive around the borehole up to the jack contact point at $\theta=45^{\circ}$. It is clear that the crack does not provide stress relief anywhere around the borehole and technlques designed to estimate in-situ stresses assuming total circumferential stress rellef near the crack can give erroneous results [4].

Similar results have been obtained for Case 8 which provides a different contact stress between the borehole and jack as delineated in the Analysis section. In obtaining results for case 8 we have taken $\sigma_{1}=\frac{2}{3} \sigma_{0}$ which insures identical jack forces $F_{y}$ for Case 7 and 8 . All results for Case 8 are within 58 of the results for Case 7 indicating that, for these two situations, a self-equilibrated contact stress distribution between jack and borehole is of little consequence. Because of this, we present no specific results for case 8. In order to evaluate the relative contributions of the jack induced stresses and the compressive in-situ stresses, we take $\sigma_{x}=\sigma_{y}=0$ for Case 9 and evaluate the circumferential borehole stresses and the crack opening displacements for the same values of $\sigma_{0}$ as obtained for case 7 . In the absence of in-situ stress, no limiting crack length exists. A representative comparison of the borehole stresses for $\sigma_{0}=2.0$ is shown in Table 5 for $b / a=1.37$ and for the limiting crack length of Case $7, b / a=1.77$. As shown, both cases exhibit the same general pattern, the effect of the insitu compressive stresses being to increase the peak compressive stress and to malntain a compressive stress around the borehole from the crack at $\theta=0$ 
to the fack at $\theta=45^{\circ}$. Similar results are shown in Table 6 for $\sigma_{0}=4.0$ and for three values of crack length.

Figures 9 and 10 compare the crack opening displacement of Case 7 and 9 for $\sigma_{0}=2.0$ and 4.0 . We note the significant reduction in crack opening caused by the compressive in-situ stress for all crack lengths and again observe the large negative crack opening gradient at the borehole associated with the large localized compressive stresses in this area. It is interesting to note that the crack opening displacement at the borehole is relatively Insensitive to both crack length and in-situ stress, depending primarily on the applied jack loading $\sigma_{0}$.

These results assume that the jack creates a single fracture opening at one point of the borehole. Tables 5 and 6 show that a tensile stress is Induced on the opposite side of the borehole, $\theta=180^{\circ}$, which is slightly greater than the stress $\frac{2}{\pi} \sigma_{0}$ just prior to the initial fracture. It is highly probably that a second crack will initiate on the opposite side of the borehole and alter the borehole stresses and crack opening displacements presented here. 


\section{References}

1. Warren, W. E., "The Quasi-Statis Stress Field Around a Fractured Well Bore," Int. J. Fracture, (to appear).

2. Schmldt, R. A., Boade, R. R., and Bass, R. C., "A New Perspective on Well Shooting - The Behavior of Contained Explosives and Deflagrations," SPE Paper \#8346 (1979), Proc. 1979 Annual SPE Meeting, Las Vegas, NV.

3. Warpinski, N. R., Schmidt, R. A., Cooper, P. W., Walling, H. C., and Northrup, D. A., "High Energy Gas Frac: Multiple Fracturing in a Wellbore," Proc. 20th U.S. Symposium on Roch Mechanics, Austin, TX (1979), pp. 143-152.

4. de la Cruz, R. V., "Jack Fracturing Technique of Stress Measurement," Rock Mechanics, 9 (1977), pp. 27-42.

5. de la Cruz, R. V., "Modifled Borehole Jack Method for Elastic Property Determination in Rocks," Rock Mechanics, 10 (1978), pp. 221-239.

6. Exdogan, F., and Gupta, G. D., "On the Numerical Solution of Singular Integral Equations," Quart. Appl. Math, (1972) pp. 525-534.

7. Khristianovic, S. A., and Zheltov, Y. P., "Formation of Vertical Fractures by Means of Highly Viscous Iiquid," Proc. 4th world Pet. Conf. - Sec. II, (1955) pp. 579-586.

8. Geertsma, J., and deklerk, F., "A Rapid Method of Predicting width and Extent of Hydraulically Induced Fractures," J. Pet. Tech., (Dec. 1969), pp. 1571-1581.

9. Shuck, L. Z., and Advani, S. H., Induced Stresses in Hydraulic Fracturing Operations, Energy Research Report, Morgantown Energy Research Center ( Sept. 1973).

10. Muskhelishvili, N. I., Some Basic Problems of the Mathematical Theory of Elastlcity, 3rd Ed., translated by J. R. M. Radok, P. Noordhoff, Ltd., Gronengen, Holland (1953). 
Table 1

Borehole Stress for $b / a=1.89$; Case $1,2,3,4$.

$$
-\sigma_{\theta \theta}(\theta) \times 10^{-3}
$$

\begin{tabular}{|c|c|c|c|c|}
\hline$\theta$ & Case 1 & Case 2 & Case 3 & Case 4 \\
\hline 0 & 0 & 5.0 & 5.0 & 5.0 \\
\hline 0.05 & 9.90 & 19.2 & 23.2 & 20.4 \\
\hline 0.10 & 33.7 & 53.5 & 66.9 & 57.2 \\
\hline 0.15 & 59.5 & 90.7 & 114 & 97.3 \\
\hline 0.20 & 78.8 & 118 & 150 & 127 \\
\hline 0.25 & 89.4 & 134 & 169 & 144 \\
\hline 0.30 & 92.7 & 138 & 175 & 149 \\
\hline 0.40 & 87.2 & 131 & 165 & 140 \\
\hline 0.50 & 76.7 & 115 & 146 & 124 \\
\hline 1.0 & 41.5 & 64.7 & 81.2 & 69.0 \\
\hline 2.0 & 21.1 & 35.4 & 43.8 & 37.8 \\
\hline 3.0 & 14.1 & 25.4 & 31.0 & 27.0 \\
\hline 4.0 & 10.6 & 20.3 & 24.5 & 21.6 \\
\hline 5.0 & 8.42 & 17.3 & 20.6 & $18 \cdot 3$ \\
\hline 10.0 & 4.01 & 11.5 & 12.7 & 12.0 \\
\hline 15.0 & 2.40 & 9.65 & 9.79 & 9.82 \\
\hline 20.0 & 1.46 & 8.43 & 7.90 & 8.39 \\
\hline 30.0 & 0.30 & 6.24 & 5.10 & 5.94 \\
\hline 40.0 & -0.32 & 4.26 & 3.11 & 3.91 \\
\hline 50.0 & -0.58 & 2.73 & 1.78 & 2.42 \\
\hline 60.0 & -0.64 & 1.63 & 0.93 & 1.40 \\
\hline 70.0 & -0.62 & 0.83 & 0.35 & 0.67 \\
\hline 80.0 & -0.66 & 0.16 & -0.12 & 0.07 \\
\hline 90.0 & -0.82 & -0.48 & -0.61 & -0.53 \\
\hline 180.0 & -5.60 & -6.63 & $-6 \cdot 30$ & -6.52 \\
\hline
\end{tabular}


Table 2

Borehole stress for $b / a=3.85$; Case $1,2,3,4$.

$-\sigma_{\theta \theta}(\theta) \times 10^{-3}$

\begin{tabular}{|c|c|c|c|c|}
\hline$\theta$ & Case 1 & Case 2 & Case 3 & Case 4 \\
\hline 0 & 0 & 5.0 & 5.0 & 5.0 \\
\hline 0.05 & 0.88 & 5.16 & 5.79 & 5.33 \\
\hline 0.10 & 3.41 & 5.63 & 8.06 & 6.28 \\
\hline 0.15 & 7.26 & 6.33 & 11.5 & 7.72 \\
\hline 0.20 & 12.0 & 7.20 & 15.7 & 9.49 \\
\hline 0.25 & 17.0 & 8.13 & 20.3 & 11.4 \\
\hline 0.30 & 22.0 & 9.04 & 24.8 & 13.3 \\
\hline 0.40 & 30.5 & 10.6 & 32.4 & 16.4 \\
\hline 0.50 & 36.0 & 11.6 & 37.4 & 18.5 \\
\hline 1.0 & 34.8 & 11.4 & 36.3 & 18.1 \\
\hline 2.0 & 19.4 & 8.56 & 22.4 & 12.3 \\
\hline 3.0 & 13.1 & 7.39 & 16.8 & 9.91 \\
\hline 4.0 & 9.81 & 6.81 & 13.9 & 8.70 \\
\hline 5.0 & 7.82 & 6.46 & 12.1 & 7.99 \\
\hline 10.0 & 3.69 & 5.93 & 8.66 & 6.70 \\
\hline 15.0 & 2.19 & 5.96 & 7.57 & 6.46 \\
\hline 20.0 & 1.38 & 6.11 & 6.99 & 6.44 \\
\hline 30.0 & 0.52 & 6.29 & 6.17 & 6.37 \\
\hline 40.0 & 0.12 & 6.08 & 5.32 & 5.96 \\
\hline 50.0 & -0.05 & 5.46 & 4.38 & 5.21 \\
\hline 60.0 & -0.12 & 4.49 & 3.39 & 4.21 \\
\hline 70.0 & -0.20 & 3.30 & $2 \cdot 34$ & 3.04 \\
\hline 80.0 & -0.37 & 1.94 & 1.26 & 1.75 \\
\hline 90.0 & -0.67 & 0.47 & 0.11 & 0.37 \\
\hline 180.0 & -6.09 & -10.0 & -8.61 & -9.54 \\
\hline
\end{tabular}


Table 3

Borehole stress for $b / a=9.47$, case $1,2,3,4$.

$$
-\sigma_{\theta \theta}(\theta) \times 10^{-3}
$$

\begin{tabular}{|c|c|c|c|c|}
\hline$\theta$ & Case 1 & Case 2 & Case 3 & Case 4 \\
\hline 0 & & 5.0 & 5.0 & 5.0 \\
\hline 0.05 & & 4.78 & 4.93 & 4.82 \\
\hline 0.10 & & 4.14 & 4.72 & 4.30 \\
\hline 0.15 & & 3.09 & 4.39 & 3.44 \\
\hline 0.20 & $\mathrm{NA}$ & 1.68 & 3.94 & 2.29 \\
\hline 0.25 & & -0.03 & 3.39 & 0.89 \\
\hline 0.30 & & -2.01 & 2.76 & -0.72 \\
\hline 0.40 & & -6.45 & 1.33 & -4.35 \\
\hline 0.50 & & -11.1 & -0.17 & -8.18 \\
\hline 1.0 & & -27.3 & $-5 \cdot 34$ & -21.4 \\
\hline 2.0 & & -24.2 & $-4 \cdot 34$ & -18.8 \\
\hline 3.0 & NA & -15.9 & -1.68 & -12.0 \\
\hline 4.0 & & -10.8 & -0.06 & -7.92 \\
\hline 5.0 & & -7.67 & 0.96 & -5.34 \\
\hline 10.0 & & -1.09 & 3.18 & 0.06 \\
\hline 15.0 & & 1.38 & 4.10 & 2.13 \\
\hline 20.0 & & 2.82 & 4.68 & 3.35 \\
\hline 30.0 & & 4.54 & 5.35 & 4.82 \\
\hline 40.0 & NA & 5.42 & 5.53 & 5.53 \\
\hline 50.0 & & 5.59 & 5.26 & 5.59 \\
\hline 60.0 & & 5.11 & 4.56 & 5.04 \\
\hline 70.0 & & 4.02 & 3.47 & 3.94 \\
\hline 80.0 & & 2.38 & 2.04 & 2.35 \\
\hline 90.0 & & 0.29 & 0.34 & 0.37 \\
\hline 180.0 & & -16.8 & -13.1 & -15.7 \\
\hline
\end{tabular}


Table 4

Borehole Stress for $b / a=1.89,3.85,9.47$; Case 5, 6 .

$-\sigma_{\theta \theta}(\theta) \times 10^{-3}$

$\mathrm{b} / \mathrm{a}=1.89 \quad \mathrm{~b} / \mathrm{a}=3.85 \quad \mathrm{~b} / \mathrm{a}=9.47$

Case 5 Case 6

Case 5 Case 6

Case 5 Case 6

\begin{tabular}{|c|c|c|c|c|c|c|}
\hline 0 & 0 & 5.00 & 0 & 5.00 & 0 & 5.00 \\
\hline 0.05 & 8.72 & 18.1 & 0.61 & 4.89 & 0.08 & 4.71 \\
\hline 0.10 & 29.7 & 49.5 & 2.36 & 4.57 & 0.33 & 3.84 \\
\hline 0.15 & 52.4 & 83.6 & 5.02 & 4.09 & 0.72 & 2.44 \\
\hline 0.20 & 69.5 & 109 & 8.27 & 3.51 & 1.25 & 0.55 \\
\hline 0.25 & 78.8 & 123 & 11.8 & 2.87 & 1.90 & -1.76 \\
\hline 0.30 & 81.7 & 127 & 15.2 & 2.25 & 2.65 & -4.41 \\
\hline 0.40 & 76.8 & 120 & 21.1 & 1.19 & 4.33 & -10.4 \\
\hline 0.50 & 67.5 & 106 & 24.9 & 0.50 & 6.10 & -16.7 \\
\hline 1.0 & 36.6 & 59.8 & 24.1 & 0.55 & 12.2 & -38.4 \\
\hline 2.0 & 18.6 & 32.9 & 13.4 & 2.57 & 11.0 & -34.1 \\
\hline 3.0 & 12.5 & 23.7 & 9.04 & 3.37 & 7.89 & -23.0 \\
\hline 4.0 & 9.35 & 19.1 & 6.80 & 3.80 & 5.98 & -16.2 \\
\hline 5.0 & 7.47 & 16.4 & 5.43 & 4.07 & 4.79 & -12.0 \\
\hline 10.0 & 3.64 & 11.2 & $2 \cdot 58$ & 4.82 & $2 \cdot 28$ & -3.16 \\
\hline 15.0 & 2.20 & 9.44 & 1.50 & 5.27 & 1.31 & 0.06 \\
\hline 20.0 & 1.23 & 8.20 & 0.83 & 5.55 & 0.69 & 1.81 \\
\hline 30.0 & -0.35 & 5.58 & -0.18 & 5.59 & -0.24 & 3.59 \\
\hline 40.0 & -1.65 & 2.93 & -1.07 & 4.89 & -1.05 & 4.11 \\
\hline 50.0 & -2.68 & -0.63 & -1.90 & 3.60 & -1.82 & 3.73 \\
\hline 60.0 & -3.45 & -1.19 & $-2 \cdot 68$ & 1.94 & -2.56 & 2.61 \\
\hline 70.0 & -4.03 & -2.58 & -3.38 & 0.12 & -3.27 & 0.91 \\
\hline 80.0 & -4.46 & -3.64 & -4.00 & -1.70 & -3.93 & -1.22 \\
\hline 90.0 & -4.79 & -4.45 & -4.54 & -3.40 & -4.54 & -3.60 \\
\hline 180.0 & -5.69 & -6.72 & -6.50 & -10.4 & -7.16 & -18.0 \\
\hline
\end{tabular}


Borehole Stress for $b / a=1.37,1.77$, Case 7,9 with $\sigma_{0}=2.0$.

$$
-\sigma_{\theta \theta}(\theta) \times 10^{-3}
$$

$$
b / a=1.37
$$

\begin{tabular}{|c|c|c|c|c|}
\hline$\theta$ & Case 7 & Case 9 & Case 7 & Case 9 \\
\hline 0 & 0 & 0 & 0 & 0 \\
\hline 0.05 & 24.0 & 22.0 & 4.74 & 3.56 \\
\hline 0.10 & 55.0 & 50.5 & 15.5 & 11.7 \\
\hline 0.15 & 63.5 & 58.4 & 26.2 & 19.7 \\
\hline 0.20 & 59.2 & 54.3 & 33.0 & 24.8 \\
\hline 0.25 & 51.7 & 47.5 & 35.8 & 26.9 \\
\hline 0.30 & 44.7 & 41.1 & 35.7 & 26.9 \\
\hline 0.40 & 34.4 & 31.6 & 32.0 & 24.1 \\
\hline 0.50 & 27.8 & 25.6 & 27.4 & 20.6 \\
\hline 1.0 & 14.2 & 13.1 & 14.5 & 10.9 \\
\hline 2.0 & 7.18 & 6.61 & 7.36 & 5.54 \\
\hline 3.0 & 4.78 & 4.42 & 4.91 & 3.71 \\
\hline 4.0 & 3.56 & 3.33 & 3.66 & 2.78 \\
\hline 5.0 & 2.81 & 2.67 & 2.89 & 2.21 \\
\hline 10.0 & 1.25 & 1.27 & 1.29 & 1.06 \\
\hline 15.0 & 0.66 & 0.60 & 0.74 & 0.60 \\
\hline 20.0 & 0.39 & 0.12 & 0.51 & 0.30 \\
\hline 25.0 & 0.32 & -0.23 & 0.46 & 0.04 \\
\hline 30.0 & 0.38 & -0.50 & 0.52 & -0.18 \\
\hline 35.0 & 0.54 & -0.69 & 0.67 & -0.37 \\
\hline 40.0 & 0.76 & -0.84 & 0.87 & -0.54 \\
\hline 45.0 & 1.02 & -0.95 & 1.12 & -0.68 \\
\hline 180.0 & -1.33 & -1.41 & $-1 \cdot 36$ & -1.48 \\
\hline
\end{tabular}

$$
\mathrm{b} / \mathrm{a}=1.77
$$


Table 6

Borehole Stress for $b / a=1.37,1.89,2.66$; Case 7,9 with $\sigma_{0}=4.0$.

$$
-\sigma_{\theta \theta}(\theta) \times 10^{-3}
$$

\begin{tabular}{|c|c|c|c|c|c|c|}
\hline \multirow[b]{2}{*}{$\theta$} & \multicolumn{2}{|c|}{$b / a=1.37$} & \multicolumn{2}{|c|}{$b / a=1.89$} & \multicolumn{2}{|c|}{$\mathrm{b} / \mathrm{a}=2.66$} \\
\hline & Case 7 & Case 9 & Case 7 & Case 9 & Case 7 & Case 9 \\
\hline 0 & 0 & 0 & 0 & 0 & 0 & 0 \\
\hline 0.05 & 44.9 & 44.1 & 5.86 & 5.02 & 1.66 & 1.22 \\
\hline 0.10 & 103 & 101 & 19.9 & 17.1 & 6.18 & 4.55 \\
\hline 0.15 & 119 & 117 & 35.2 & 30.2 & 12.5 & 9.18 \\
\hline 0.20 & 110 & 109 & 46.6 & 40.0 & 19.2 & 14.1 \\
\hline 0.25 . & 96.7 & 94.9 & 52.9 & 45.3 & $25 \cdot 3$ & 18.7 \\
\hline 0.30 & 83.6 & 82.1 & 54.8 & 47.0 & 30.2 & 22.2 \\
\hline 0.40 & 64.4 & 63.3 & 51.6 & 44.2 & 35.7 & 26.3 \\
\hline 0.50 & 52.1 & 51.2 & 45.3 & 38.9 & 36.7 & 27.0 \\
\hline 1.0 & 26.6 & 26.2 & 24.5 & 21.0 & 25.0 & 18.4 \\
\hline 2.0 & 13.4 & 13.2 & 12.5 & 10.7 & 12.9 & 9.53 \\
\hline 3.0 & 8.97 & 8.85 & 8.36 & 7.18 & 8.68 & 6.40 \\
\hline 4.0 & 6.72 & 6.66 & 6.24 & 5.38 & 6.50 & 4.80 \\
\hline 5.0 & 5.35 & 5.34 & 4.95 & 4.29 & 5.17 & 3.83 \\
\hline 10.0 & 2.46 & 2.54 & 2.29 & 2.04 & 2.39 & 1.79 \\
\hline 15.0 & 1.24 & 1.20 & 1.32 & 1.16 & 1.39 & 1.01 \\
\hline 20.0 & 0.52 & 0.25 & 0.82 & 0.59 & 0.88 & 0.52 \\
\hline 25.0 & 0.11 & -0.47 & 0.54 & 0.12 & 0.61 & 0.13 \\
\hline 30.0 & -0.08 & -1.00 & 0.40 & -0.30 & 0.48 & -0.20 \\
\hline 35.0 & -0.12 & -1.39 & 0.37 & -0.66 & 0.46 & -0.50 \\
\hline 40.0 & -0.04 & -1.68 & 0.42 & -0.99 & 0.52 & -0.77 \\
\hline 45.0 & -0.11 & -1.90 & 0.53 & -1.27 & 0.52 & -1.02 \\
\hline 80.0 & -2.68 & -2.82 & -2.79 & -3.01 & -2.84 & -3.19 \\
\hline
\end{tabular}




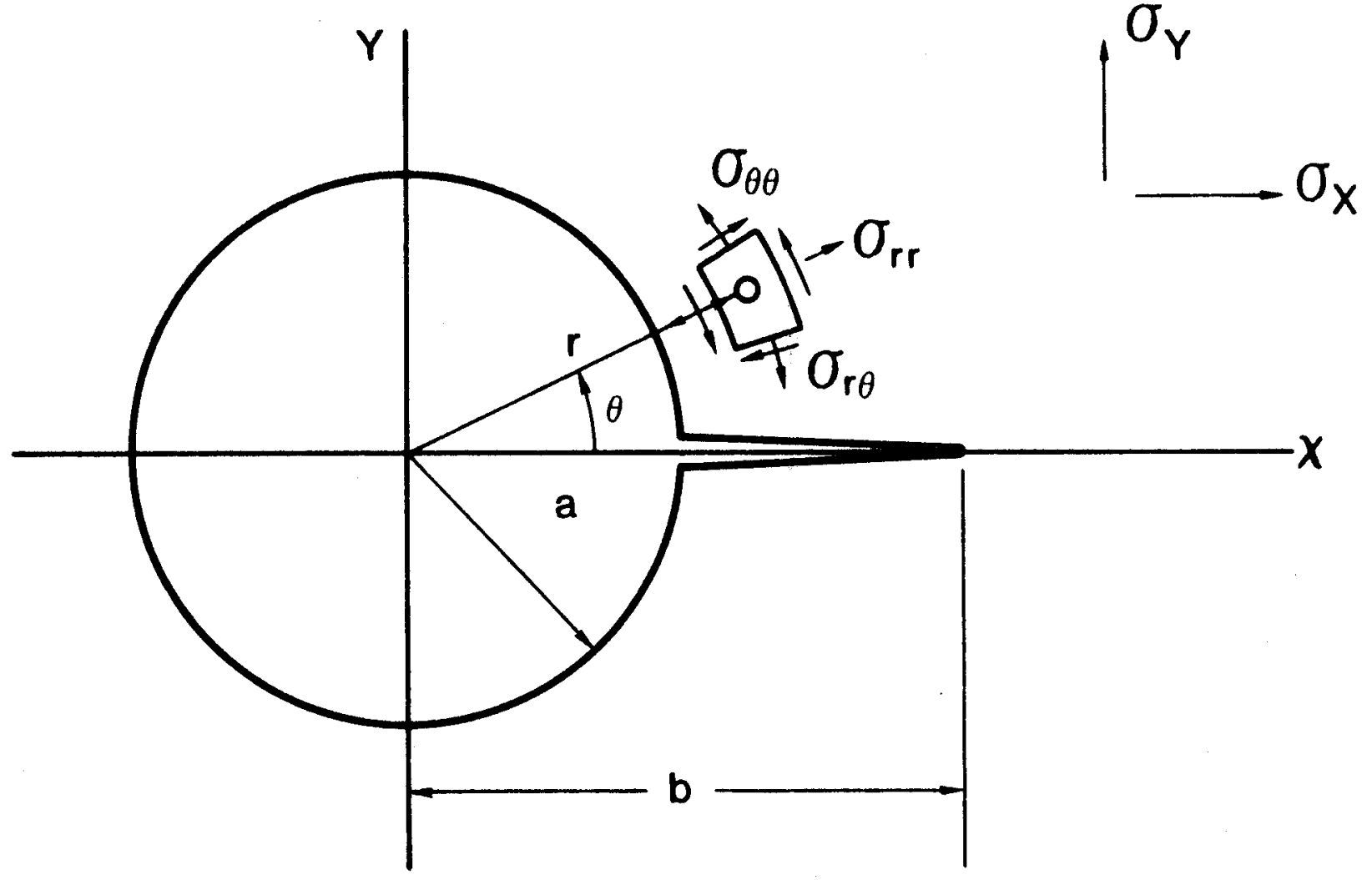

Figure 1. Geometry of Borehole with Crack 


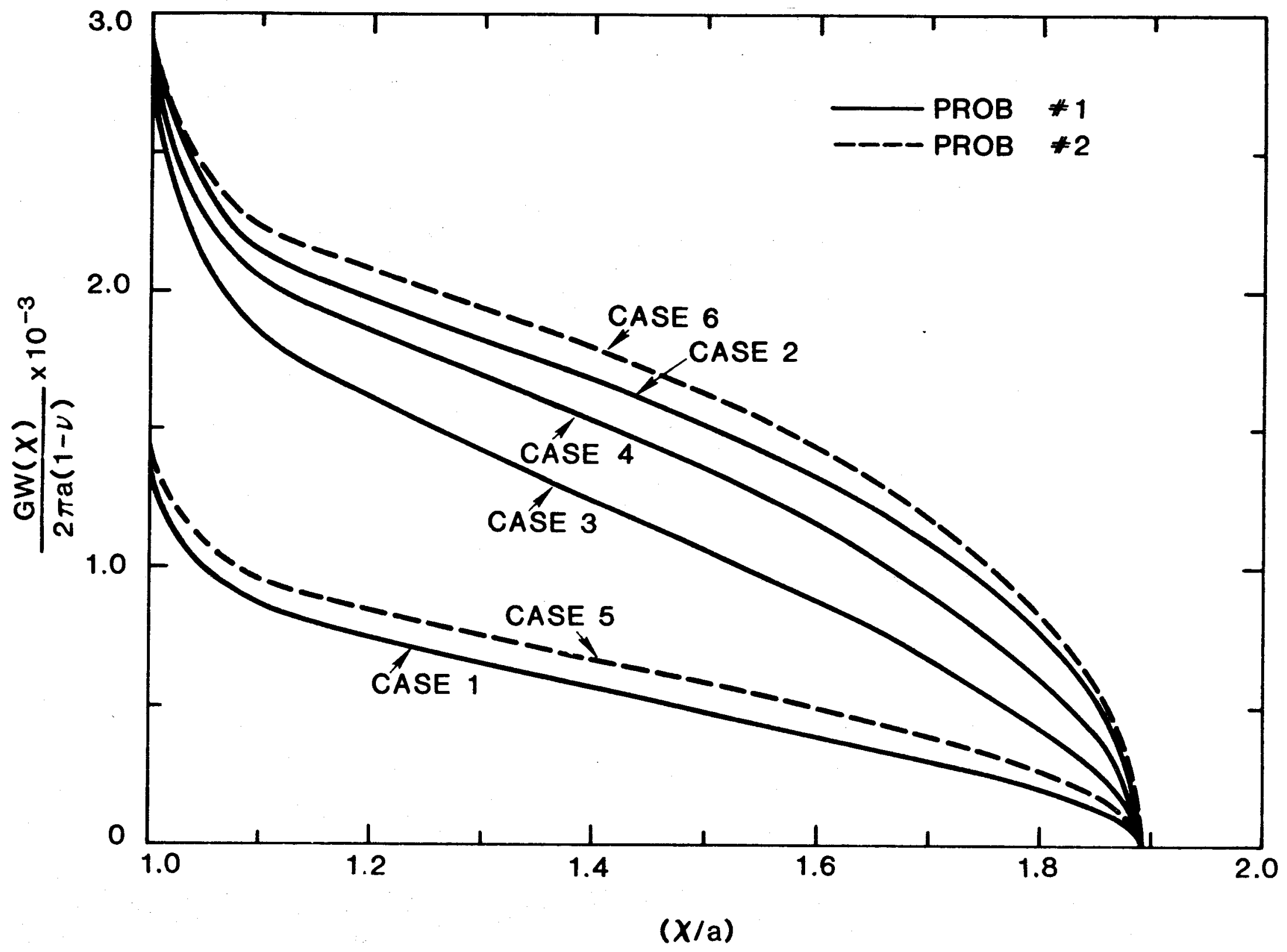




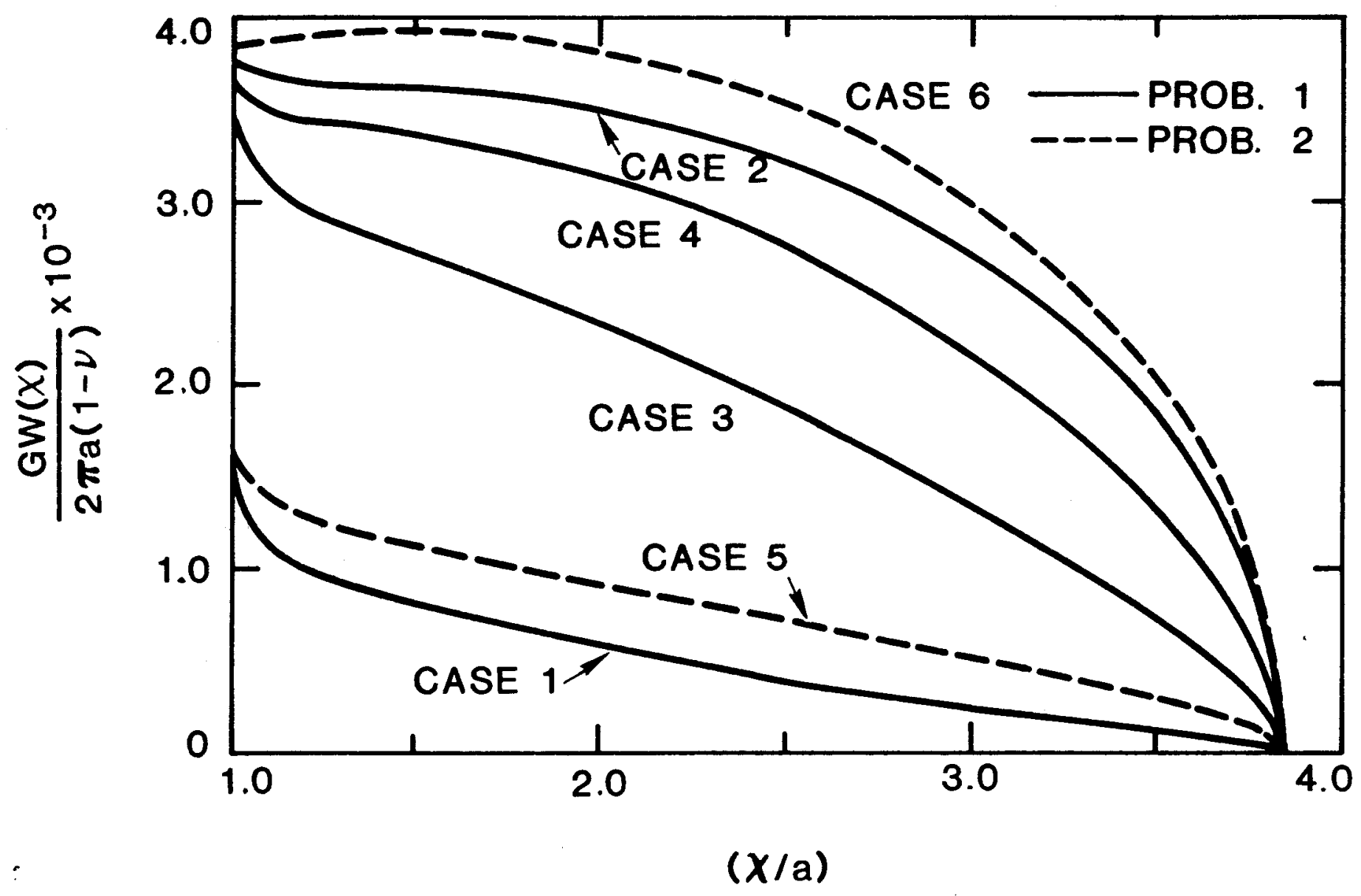

Figure 3. Crack Opening Displacement for b/a $=3.85$. Case 1, 2, 3, 4, 5, 6 . 


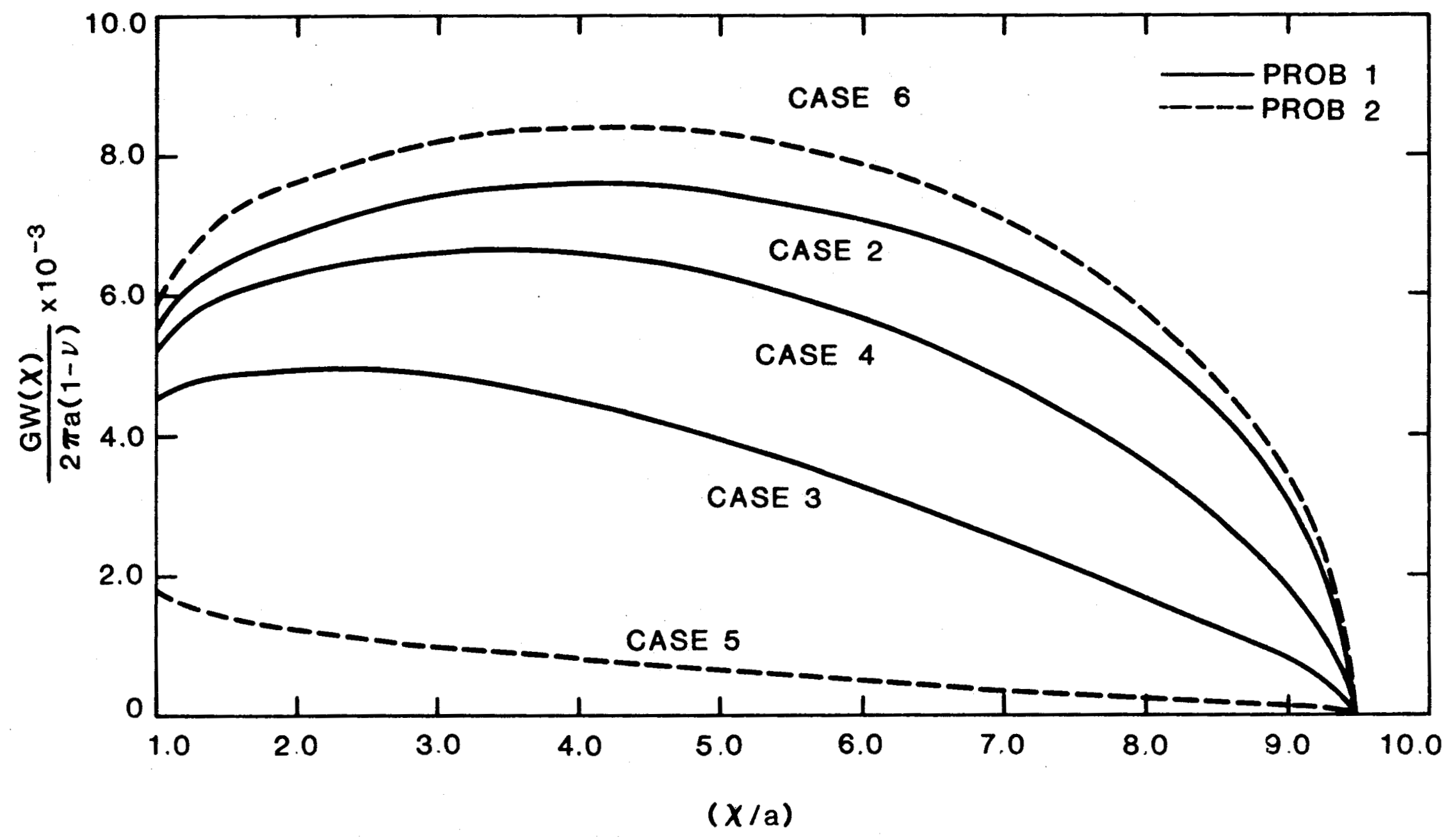

Figure 4. Crack Opening Displacement for $b / a=9.47$. Case 1, 2, 3, 4, 5, 6 . 


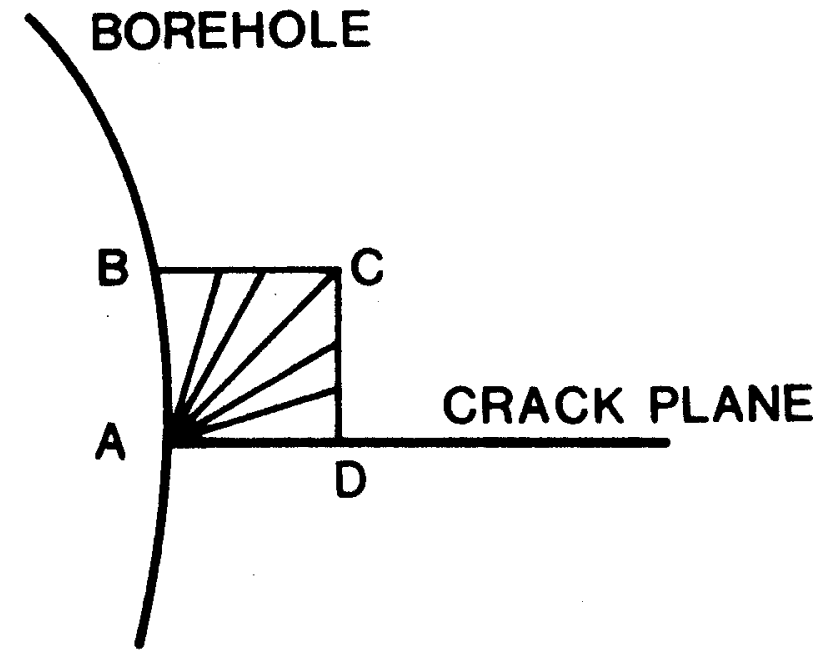

a) BEFORE FRACTURE

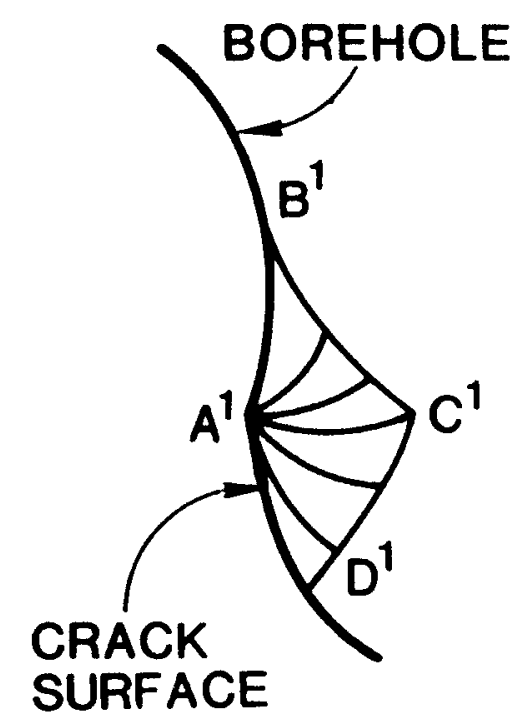

(b) AFTER FRACTURE

Figure 5. Strained Element at Corner of Borehole and Crack. 


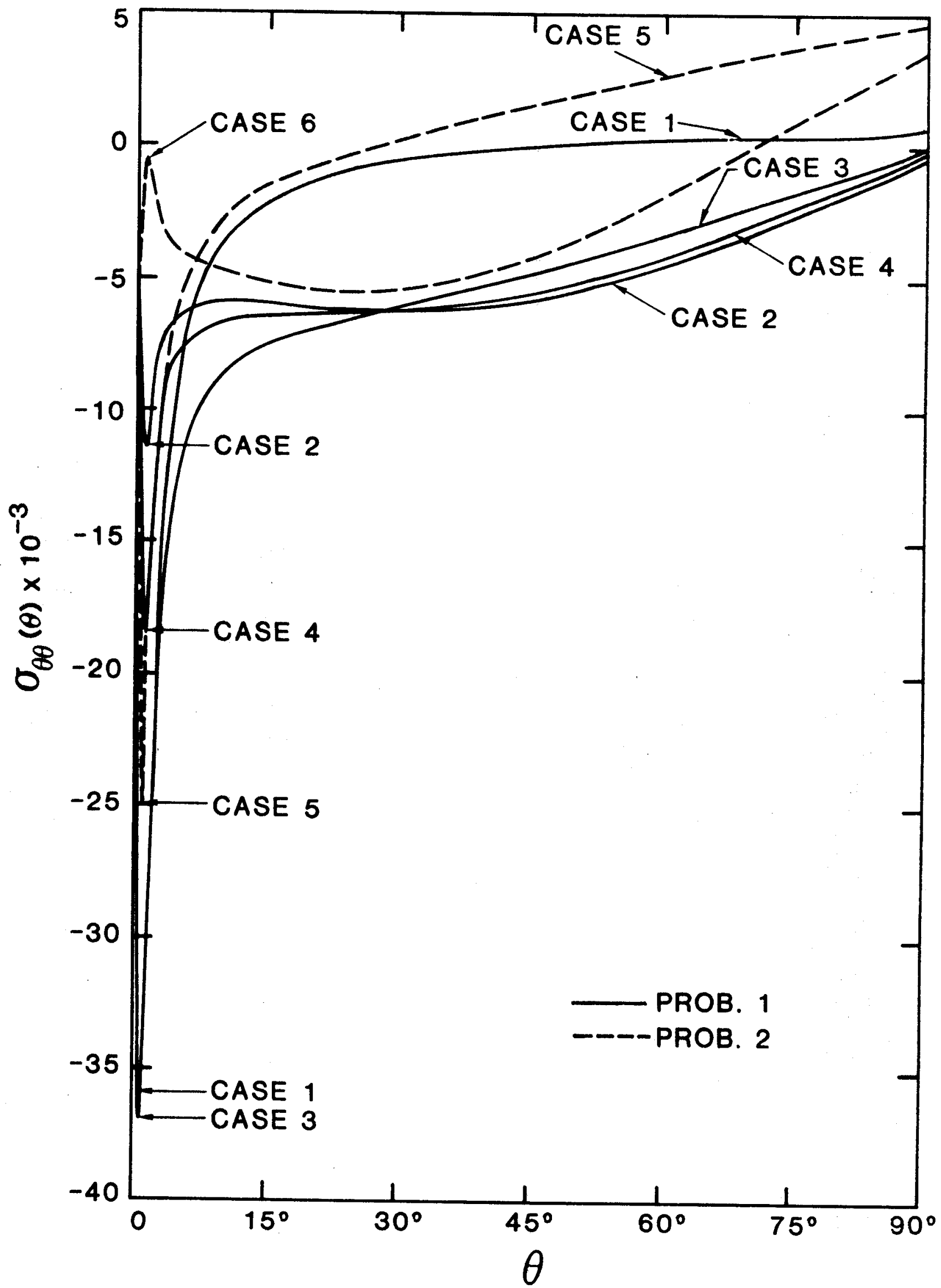

Figure 6. Borehole Stress for $b / a=3.85$. Case 1, 2, 3, 4, 5, 6 . 


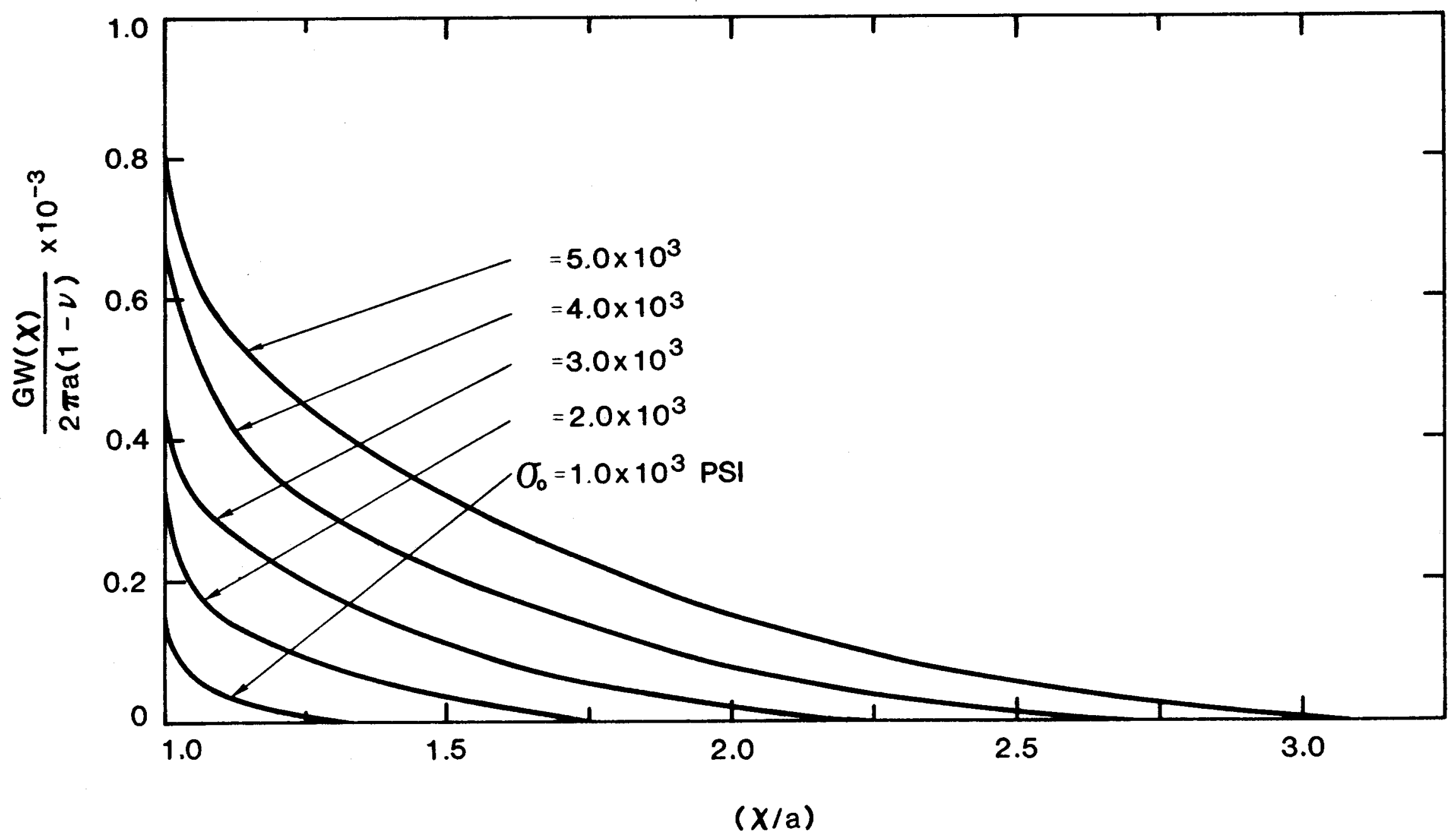

Figure 7. Crack Opening Displacement at Limiting Length. Case 7 with $\sigma_{0}=1,2,3,4,5 \times 10^{3}$ psi. 


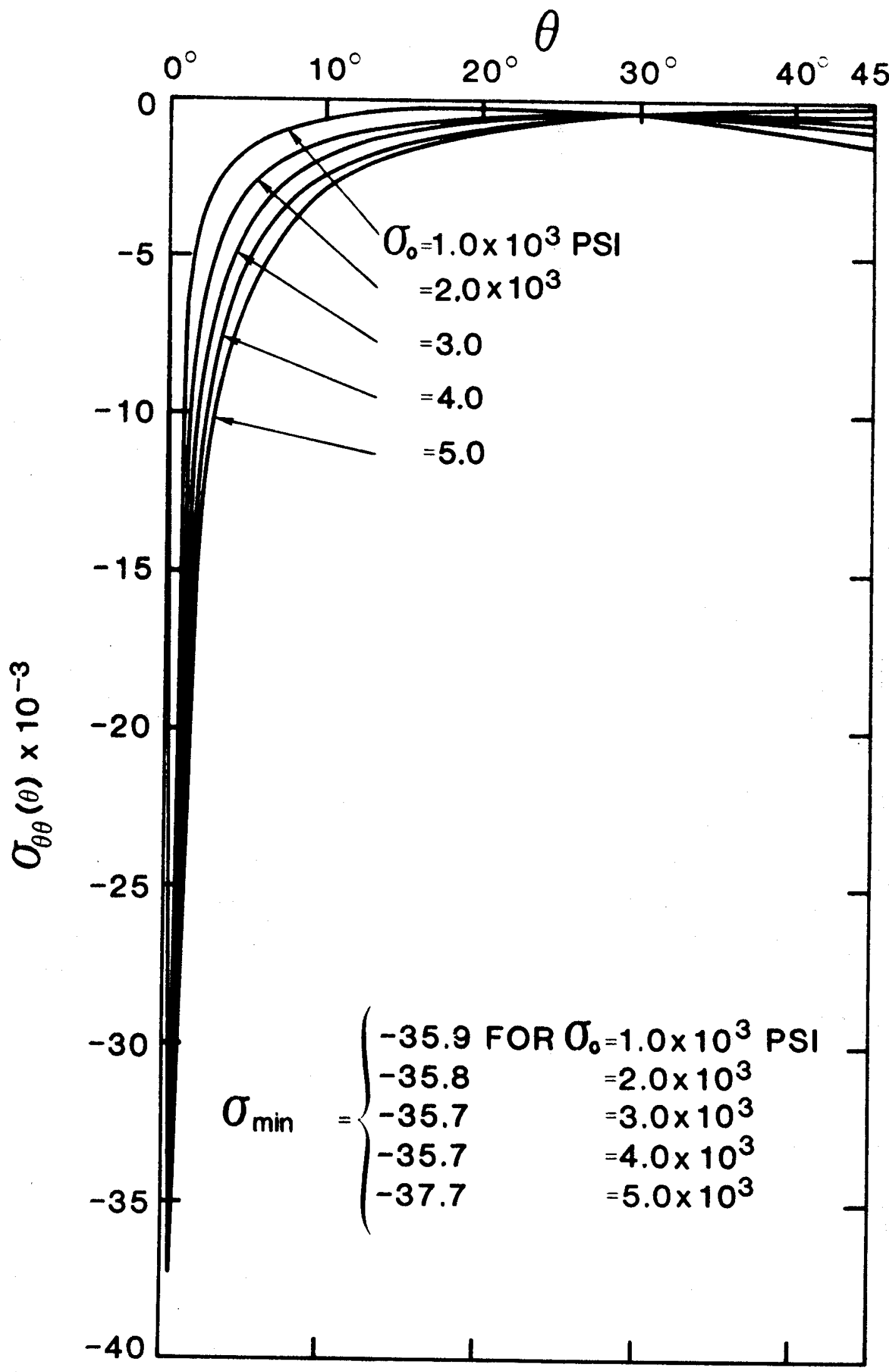

Figure 8. Borehole Stress for Limiting Crack Length. Case 7 with $\sigma_{0}=$
$1,2,3,4,5 \times 10^{3}$ psi. 


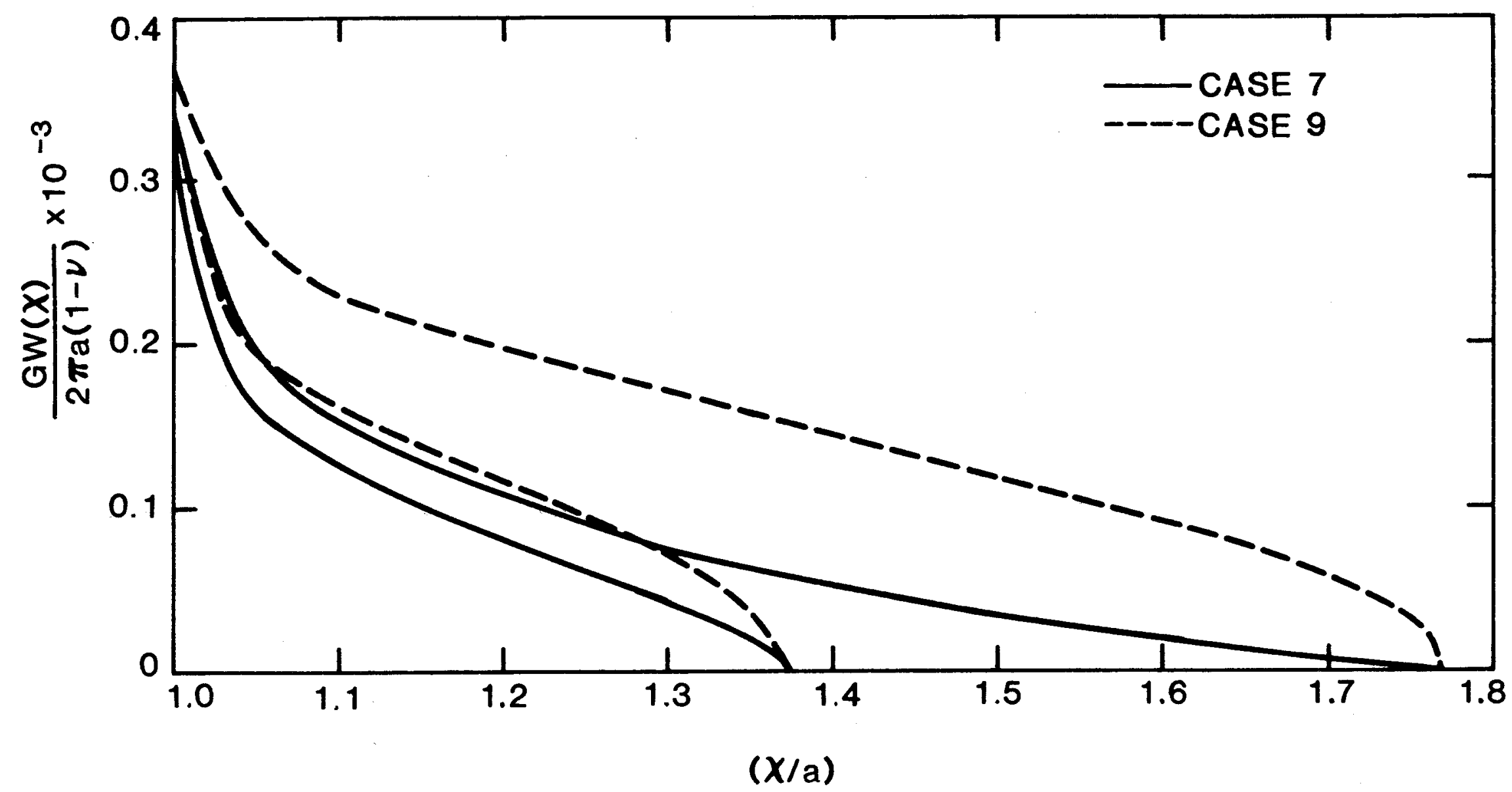

Figure 9. Crack Opening Displacement for $\mathrm{b} / \mathrm{a}=1.37,1.77$. Case 7 and 9 with $0_{0}=2.0 \times 10^{3}$ psi. 


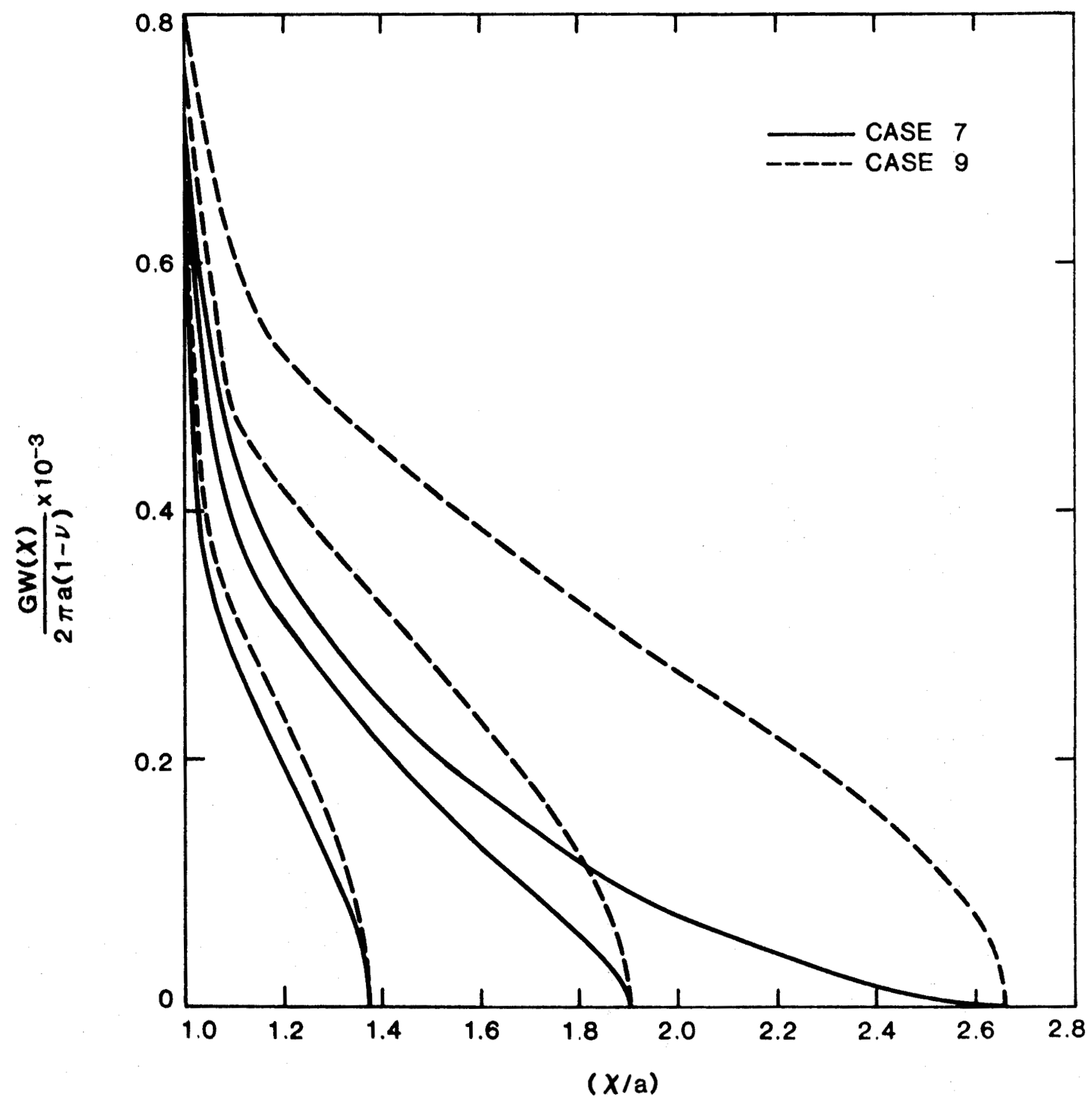

Figure 10. Crack Opening Displacement for $b / a=1.37,1.89,2.66$. Case 7 and 9 with $\sigma_{0}=4.0 \times 10^{3} \mathrm{psi}$. 
Distribution:

1100 C. D. Broyles

1110 J. D. P1impton

1111 R. C. Bass

1112 C. R. Meh1

1112 C. W. Smith

1132 P. W. Cooper

1133 R. D. Statler

1133 W. C. Vollendorf

1725 H. C. Walling

4747 R. R. Boade

4752 R. A. Schmidt

4753 D. A. Northrop

4753 J. A. Clark

4753 N. R. Warpinski

5500 O. E. Jones

5510 D. B. Hayes

5520 T. B. Lane

5530 W. Herrmann

5531 P. F. Martinez (4)

5532 B. M. Butcher

5532 W. R. Wawersik

5533 A. J. Chabai

5534 J. R. Asay

5800 R. S. Claassen

Attn: 5820 R. E. Whan

5830 M. J. Davis

5840 N. J. Magnani

5810 R. G. Kepler

5814 F. P. Gerstle, Jr.

5814 W. E. Warren (4)

8266 Tech. Library

3141 Tech. Library (5)

3151 Tech. Writing (3)

For DOE/TIC (Unlimited Release)

DOE/TIC (25)

(C. Dalin, 3154-3)

University of Wisconsin (1)

1509 University Ave.

Madison, WI 53706

ATTN: R. de la Cruz

Science Applications, Inc. (I)

Suite, Chestnut Ridge Prof. Bldg.

Morgantown, WV

ATTN: L. Z. Shuck

She1l Research

Shell Mex. House

Steamer, London

WC2R ODX

United Kingdom

ATTN : J. Geertsma 